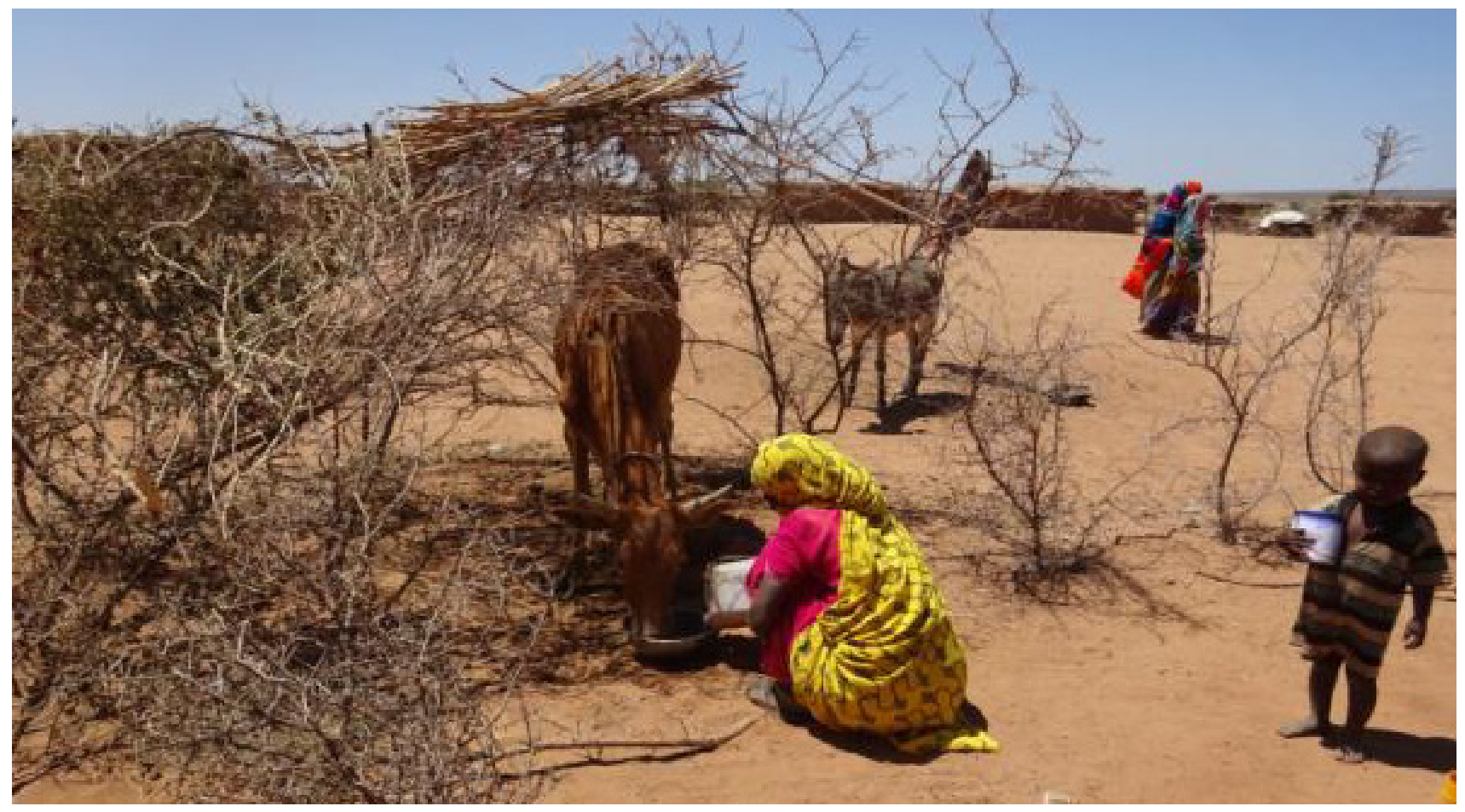

Women collecting firewood. Asbuli Kebele, Erer Woreda, Siti Zone, March 2016. Photo: Luisa Dietrich.

\title{
CONSOLIDATED GENDER ANALYSIS FOR THE ETHIOPIAN DROUGHT RESPONSE
}

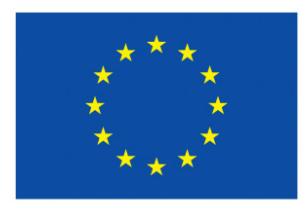

Humanitarian Aid and Civil Protection
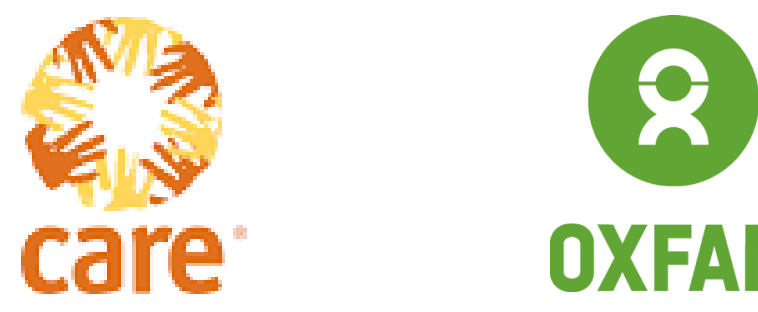

OXFAM 


\section{CONTENTS}

1. Introduction

1.1. ETHIOPIA: COUNTRY PROFILE AND GENDER INEQUALITY ..................................................

1.2. THE HUMANITARIAN CONTEXT OF THE CURRENT DROUGHT ...............................................11

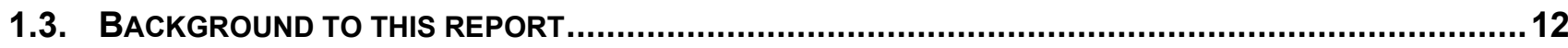

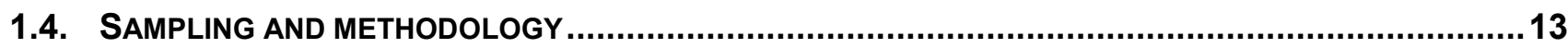

2. IMPACT OF THE DROUGHT ON MEN, WOMEN, GIRLS AND BOYS 14

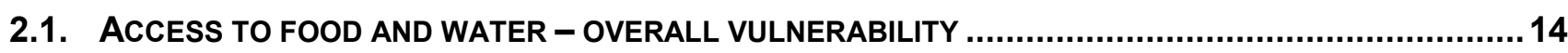

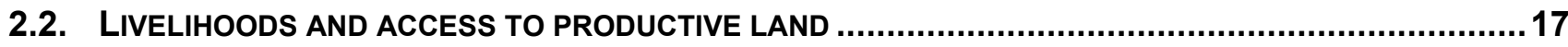

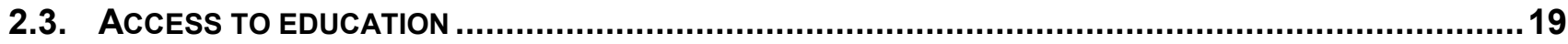

2.4. HEALTH, INCLUDING SEXUAL AND REPRODUCTIVE HEALTH............................................. 19

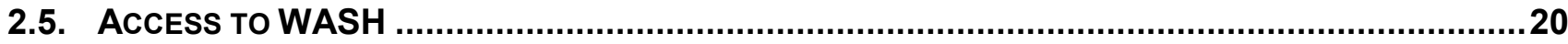

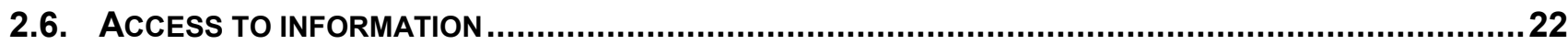

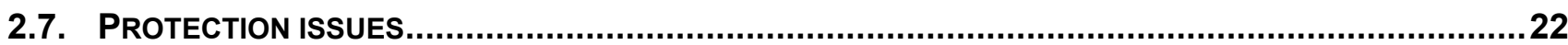

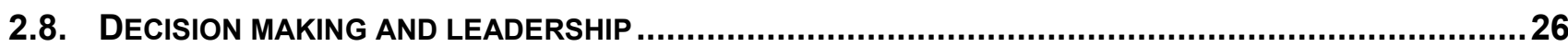

3. CHANGING GENDER DYNAMICS AND COPING STRATEGIES 27

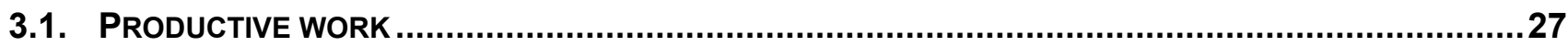

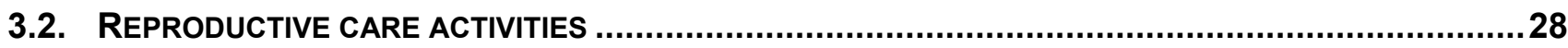

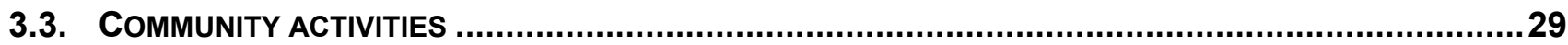

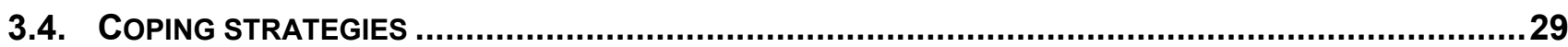

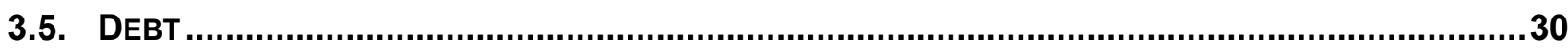

4. PRIORITIES AND OPPORTUNITIES FOR GENDER-RESPONSIVE PROGRAMMING 31

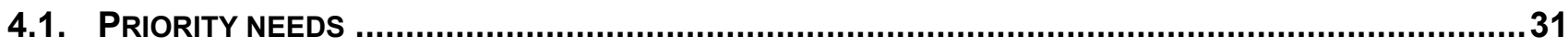

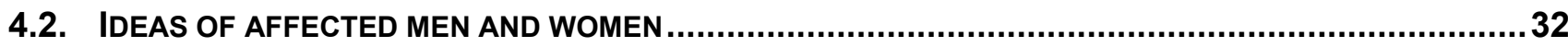

5. HUMANITARIAN COORDINATION

6. RECOMMENDATIONS $\quad 34$

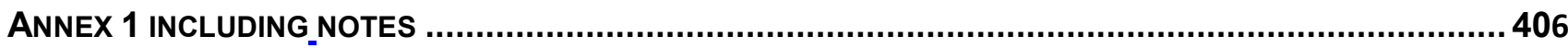




\section{FIGURES AND TABLES}

Figure 1: Map of the drought 'hotspot' areas in Ethiopia

Figure 2: Perceptions of the most food-insecure population groups in Somali and Afar regions

Figure 3: Priorities for food intake in households in Somali and Afar regions

Figure 4: Oxfam survey data on how livelihoods have been affected by the drought, among 179 respondents

Figure 5: Use of latrines in Siti Zone and Zone 2

Figure 6: What are the main reasons for tensions within the household?

Figure 7: What is borrowed money used for?

Figure 8: Preferred cash-for-work activities for women and men

Table 1: Oxfam study on gender-related decision making among 179 respondents in Afar and Somali regions

Table 2: Household engagement in community activities among 179 respondents in Afar and 


\section{Acronyms and abbreviations}

\begin{tabular}{ll} 
CCRDA & Consortium of Christian Relief and Development Associations \\
CFW & Cash-for-work \\
CSA & Central Statistical Agency \\
ECHO & European Civil Protection and Humanitarian Aid Operations \\
EDHS & Ethiopia Demographic and Health Survey \\
FGD & Focus group discussion \\
FGM/C & Female genital mutilation/cutting \\
GA & Gender analysis \\
GDP & Gross domestic product \\
GIHAWG & Gender in Humanitarian Action Working Group \\
GoE & Government of Ethiopia \\
GTP II & Growth and Transformation Plan II \\
GBV & Gender-based violence \\
HRD & Humanitarian Requirements Document \\
HTP & Harmful traditional practice \\
IDP & Internally displaced person \\
M\&E & Monitoring and evaluation \\
NFI & Non-food item \\
NGO & Non-governmental organization \\
PSEA & Prevention of sexual exploitation and abuse \\
PSNP & Productive Safety Net Programme \\
RCWDO & Rift Valley Children and Women Development Organization \\
SEA & Sexual exploitation and abuse \\
SEDA & Sustainable Environment and Development Action \\
SGBV & Sexual and gender-based violence \\
VSLA & Village savings and loan association \\
WASH & Water, sanitation and hygiene \\
\hline
\end{tabular}


This paper was written as a collaborative, consolidated piece comprising desk reviews and primary field studies by Oxfam and CARE Ethiopia. Oxfam acknowledges first and foremost the assistance of the affected women and men interviewed within this study for their participation and involvement in its production. This paper is part of a series of gender analyses created under an ECHO ERC funded project to institutionalise gender in the humanitarian sector. Further acknowledgements for contributions to the inception and completion of this paper include, Luisa Dietrich (Gender Advisor HSP, Oxfam GHT), Ankets Petros (Ethiopia Gender Advisor and ECHO Project Manager in country), Tess Dico-Young (Global Humanitarian Gender Advisor), Eliza Hilton (ECHO ERC Project Manager), (Tsion Amare (Oxfam Humanitarian Trainee), Valeria Vilardo (Gender Advisor HSP, Oxfam GHT), Selamawit Firrdessa (CARE Gender Advisor) and Wondimagegn Fanta (UNFPA Program Analyst Humanitarian Response), Steph Avis (Project Learning and Support Officer). We also thank all of the organisations participating in the ECHO ERC project including CARE, Childfund, GOAL Ethiopia, Concern, CCRDA, RCWDO and SEDA. The funding support of the project is through ECHO ERC.

This publication is copyright but the text may be used free of charge for the purposes of advocacy, campaigning, education, and research, provided that the source is acknowledged in full. The copyright holder requests that all such use be registered with them for impact assessment purposes. For copying in any other circumstances, or for re-use in other publications, or for translation or adaptation, permission must be secured and a fee may be charged. Email policyandpractice@oxfam.org.uk.

The information in this publication is correct at the time of going to press.

Published by Oxfam GB for Oxfam International under ISBN 978-0-85598-786-2 in September 2016.

\section{OXFAM}

Oxfam is an international confederation of 20 organizations networked together in more than 90 countries, as part of a global movement for change, to build a future free from the injustice of poverty. Please write to any of the agencies for further information, or visit www.oxfam.org.
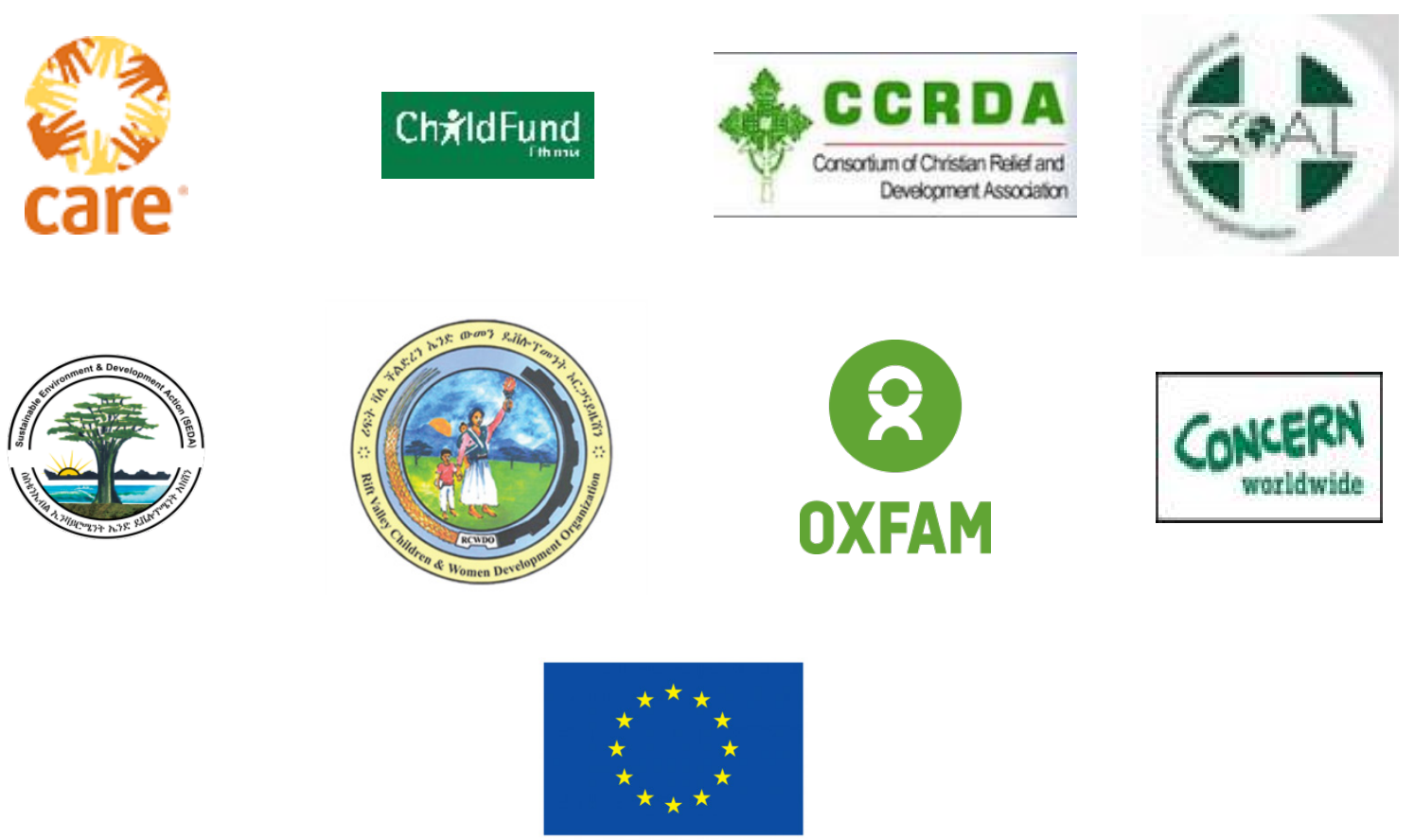

Humanitarian Aid and Civil Protection

Project funded by ECHO ERC 


\section{Executive summary}

\section{Introduction}

Drought, worsened by the effects of the El Niño phenomenon in 2015, is having a devastating impact on the lives and livelihoods of Ethiopians. According to the Government of Ethiopia (GoE) and the inter-agency mid-meher and meher seasonal assessments (the main crop production season), the number of people who will require food assistance in 2016 increased from 8.2 million in October 2015 to 10.2 million in December 2015, making Ethiopia home to the largest acutely food-insecure population in the world.

Recognizing that crisis can further exacerbate existing vulnerabilities and reinforce gender norms, a coordinated effort among humanitarian actors is crucial to mitigate the worst effects of the current drought on men and women, girls and boys. In this light, a Gender in Humanitarian Action Working Group lead by Oxfam Ethiopia has been created, consisting of eight international and local NGOs active in the country, ${ }^{1}$ with the support of the ECHO-funded project 'Gender in Emergencies: Institutionalization of Policy and Practice'. ${ }^{2}$

In order to better understand the emergency situation and to respond based on the different strategic and practical needs of women, men, girls and boys, Oxfam and CARE Ethiopia each conducted a gender analysis in March-April 2016 as part of their respective emergency responses: CARE conducted a Rapid Gender Analysis, while Oxfam carried out a Comprehensive Gender Analysis.

Oxfam's analysis was carried out in five kebeles (sub-districts) in the two regions of Somali (Siti Zone) and Afar (Zone 2), while the CARE research took place in the drought-affected areas of Oromia (East and West Harerge Zones), Amhara (South Gonder Zone) and Afar regions (Zones 1 and 3). In total, the analyses covered 21 kebeles in Somali, Oromia, Amhara and Afar regions.

Both analyses comprised over 60 questions divided into sections covering demographic information, analysis of gendered division of labour, decision making, access to and control over resources, and humanitarian assistance. The questionnaire was implemented with 179 respondents across the five kebeles.

The selection criteria for respondents in both analyses were based on purposeful and targeted sampling to reach the most vulnerable households and to achieve a gender balance among male and female respondents in each kebele. Oxfam also captured specificities of settlements for internally displaced persons (IDPs).

This report represents a consolidated set of findings and recommendations from the two gender analyses for the consideration of decision makers and practitioners in national and international humanitarian agencies, as well as the Ethiopian central and regional governments. It aims to bring together learning on the differential gendered impacts of the current drought in affected communities. These findings offer an entry point to enhance a gender-responsive approach to humanitarian action.

The document is structured into four sections. Section 1 focuses on the gendered impact of the drought, and Section 2 explores shifts in gender dynamics as a result of the drought, at household and community levels. Section 3 identifies practical entry points for a gender-responsive humanitarian drought response, while Section 4 highlights concrete recommendations for humanitarian actors. 


\section{Key findings}

\section{Impact of the drought on men, women, girls and boys}

\section{Access to food and water}

- The drought has affected men, women, girls and boys in various ways, but the most foodinsecure groups currently appear to be infants, elderly people and pregnant and lactating women.

- Infants and children are especially vulnerable because of their reduced capacity to digest available food and the lack of nutritious food in sufficient quantity, in particular the reduced availability of mother's breast milk or cow's milk.

- Women as a general category also appear to be more vulnerable than men. Women are deprioritized in household food consumption, including pregnant and lactating mothers.

- Polygamous households face a disproportionate degree of vulnerability, where humanitarian assistance may be shared out more thinly.

- Female-headed households, elderly women and disabled people were also identified as being especially vulnerable.

\section{Livelihoods and access to reproductive land}

- There does not appear to be a significant gendered difference in terms of drought-specific impacts on livelihoods.

- Loss of livestock, reduction of income and an increase in debt are the main impacts on livelihoods.

- Although agro-pastoralists are better off than pastoralists, they have still been severely affected by the drought in the areas studied.

- A reduction in income from livestock products particularly affects women, who are traditionally engaged in selling milk products to buy food for household consumption.

- Female petty traders have also been affected, since women are unable to sustain their businesses because of their responsibility for managing their households.

\section{Access to education}

- The education system is seriously affected when flooding destroys schools (in regions like Afar and Somali) and drought forces families to abandon their homes in search of food, water and protection.

- Where schools still exist, parents are not able to cover education fees.

- Education is being affected in the drought-prone regions where inadequate food intake limits the capacity of children to stay in class.

- In all affected schools, there is a high rate of absenteeism, especially among girls due to their involvement in domestic responsibilities such as walking long distances to fetch water, caring for younger siblings at home and trying to generate income.

\section{Health, including sexual and reproductive health}

- Qualitative evidence suggests that the drought has increased health problems related to sanitation, which are further exacerbated by water scarcity, pollution and contamination.

- Poor water availability, lack of sanitation, decreased food availability and displacement are factors that will significantly heighten the risks of increased mortality and morbidity, including from malnutrition and due to outbreaks of communicable diseases.

- The communities in the areas studied are mostly vulnerable to waterborne and airborne diseases and to diarrhoea.

\section{Access to WASH facilities}

- Open defecation is prevalent in all kebeles analysed in Somali and Afar regions; the main reason for not using latrines is their unavailability.

- Hand washing is not practised by the majority of community members, with no significant variation between Somali and Afar regions.

- Women and girls lack access to appropriate water and sanitation services, including access to menstrual hygiene materials. 


\section{Access to information}

- Communities who live some distance from distribution centres, especially female-headed households, lack reliable information about distributions of humanitarian assistance.

\section{Protection issues}

- In Afar region there is a protection risk to pastoralist boys, who face physical attacks as a result of conflict over pasture.

- The studies found evidence of significant psychological effects of the drought on both men and women, and the negative effects on men are becoming more severe.

- Women and girls are affected by the drought and fear sexual violence during movement for fetching water and/or collecting fire woods and domestic conflict at household level.

- Adolescent girls are more vulnerable to trafficking and to sexual and gender-based violence (SGBV).

- The studies revealed a decrease in early marriage and female genital mutilation (FGM) practices in the chosen areas due to the drought. However, such practices are still prevalent in some areas in spite of the drought.

\section{Decision making and leadership}

- Male-dominated decision-making patterns at household and community levels remain unchanged. Women have low levels of involvement in decision making around money, over freedom of movement and over bodily integrity.

\section{Changing gender dynamics and coping strategies}

\section{Productive work}

- For both women and men, the opportunities for productive income-generating activities such as petty trade, traditional milk processing and selling and the sale of livestock has significantly reduced, without any noticeable shift in the gender division of labour.

- However, a noticeable shift is evident in the gendered division of labour related to women's engagement in cash-for-work (CFW) activities.

\section{Reproductive care and community activities}

- The burden of reproductive and unpaid care activities has increased for females.

- Despite being stigmatized, a significant number of men and boys have started to engage in unpaid reproductive activities outside the home (fetching water, going to community mills), allowing a change in the gendered division of labour.

- The level of engagement in community activities has diminished for both men and women. However, men, from both IDP and host communities, tend to be more involved than women in community activities, and also report being more consulted in decision making about these activities than women.

\section{Coping strategies}

- Gendered coping mechanisms include adult pastoralist women with children resettling in IDP camps, while men and adolescent boys and girls cope with the drought by migrating to urban centres or abroad in search of jobs.

- A higher proportion of boys pursue opportunities of continued education, while girls support the increased burden of household chores.

- In the predominantly agricultural areas of Oromia and Amhara, women tend to engage in petty trade as a coping mechanism. 
Debt

- An increased amount of debt due to the drought was reported for both men and women.

\section{Priorities and opportunities for gender-responsive programming}

\section{Priority needs}

- There is no significant gendered pattern or difference across regions in terms of priory needs. The most urgent needs in all the regions analysed relate to the provision of sufficient quality and quantity of water and food (including complementary food for infants).

- Non-food items (NFIs) such as clothing, soap, jerry cans and cooking utensils are priorities in the affected areas.

- Female dignity kits, essential to help to meet women's immediate hygiene needs, are specific requirements of women and girls. These kits include shoes, scarves, menstrual cloth, underwear, soap and flashlight.

- Cash distribution options are prioritized, either through cash-for-work/training or unconditional cash transfers to enable recipients to buy their preferred food, while also strengthening the capacity of local petty traders (who are predominantly women).

\section{General recommendations}

\section{$>$ Enhanced coordination mechanisms to address complex emergencies}

Address priority needs of drought-affected populations: Ensure a coordinated approach between the government, the UN system, NGOs, religious authorities and the community in order to address the most pressing community needs, such as water and food (in adequate quality and quantity) and mobile milling solutions.

Include gendered considerations in recovery interventions: Ensure the equal participation of women in livestock restocking and training for alternative livelihood options. Recovery interventions relating to water source management and infrastructure projects should enhance women's participation and leadership. There is a need for targeted support for mixed and women's cooperatives, as well as for access to grants for small businesses to improve women's economic status.

Improved collaboration is needed between NGOs such as Oxfam, CARE and UN agencies, particularly in lobbying the government to crack down on illegal brokers who arrange early marriages.

Monitoring of GBV and harmful traditional practices (HTPs): This should be part of the monitoring and evaluation (M\&E) plan for all emergency projects and should be done jointly with government and community structures.

\section{$>$ Improve targeting practices for humanitarian assistance}

Improve the targeting of vulnerable groups, while reducing levels of vulnerability: Extend the categorization of vulnerable populations to include polygamous households and households living at sub-kebele level (far from the main village). Ensure the provision of inclusive information and registration for widows, divorced and separated women and female-headed households, and distribute specific complementary food items for infants, elderly people and pregnant and lactating women and girls. Also, ensure that higher quantities of humanitarian assistance are provided to polygamous households and to pregnant and lactating women and girls.

Extend targeting practices to include IDPs and host communities: Despite prevailing collaborative relationships between IDPs and host communities, resource scarcity limits the capacity of host communities to provide continuous support to pastoralist communities. 
Address the psychosocial impact on men: Target CFW activities for men and women, and consider targeting male beneficiaries with CFW schemes that support vulnerable populations (elderly and disabled people and pregnant or lactating women and girls). Seize the opportunity to increase men's awareness of women's overburden of work, and explore options for engaging men in reproductive labour outside the home, thus contributing to shifts in the gendered division of labour.

Take measures to reduce women's (unpaid) reproductive workload through holistic programme design: Seize opportunities to reduce women's workload through the provision of safe and reliable water supply, the rehabilitation of boreholes, and the provision of water harvesting materials and by supporting the government's efforts to complete piped water systems. Consider distributing locally produced fuel-efficient stoves and other items.

\section{$>$ Enhance holistic water, sanitation and hygiene interventions}

Install gender-specific WASH hardware: Engage in participatory and inclusive consultation mechanisms to design latrines and bathing spaces, including on locations and distance from the community. Distribute female dignity kits to women and girls based on a participatory mechanism.

Take the opportunity to significantly scale up public health promotion activities: Step up public health promotion training, with a special emphasis on hand washing, water treatment and cleaning of jerry cans. Increase the number of female community health volunteers, women's active participation and leadership in water user committees and monitoring schemes to ensure adequate water quality.

\section{Expand emergency food security and support for vulnerable livelihoods}

Expand the distribution of NFIs: The most urgently needed NFIs and female dignity kits should be ditributed to vulnerable women and girls.

Expand cash transfer programmes to increase the agency of beneficiaries: To provide cash transfers, consider food vouchers, cash-for-learning and cash-for-travel schemes to adress the needs of vulnerable poplations. Strengthen the capacity of petty traders to ensure that food is on sale.

\section{$>$ Institutionalize protection and safe programming}

Increase engagement with community leaders to monitor and prevent SGBV: Identify the prevalence of SGBV in the local context and raise awareness among kebele authorities and religious leaders around combating violence against women, while strengthening community collaborative coping mechanisms (such as going to water points in mixed-gender groups).

Strengthen inter-agency referral systems: Increase inter-agency cooperation to map a referral pathway for survivors of SGBV and victims of trafficking. Integrate psychosocial support activities into emergency response where possible; if this is not possible within the scope of the project, link with other long-term projects and services that are delivering psychosocial support. 


\section{INTRODUCTION}

\subsection{Ethiopia: country profile and gender inequality}

Ethiopia is the second most populous country in Africa, with an estimated population of 94 million in $2013 .{ }^{3}$ Despite a remarkable and continuous average real GDP growth rate of 10.8 percent per annum over the past 12 years, ${ }^{4}$ poverty remains a great challenge. The proportion of the population living in poverty in 2014/15 was estimated to be 23.4 percent, showing a substantial decline from 38.7 percent in 2003/04 in both rural and urban areas. ${ }^{5}$ During the period 2004/05 to 2010/11, income inequality measured by the Gini coefficient remained close to 30 percent. In 2014/15, agriculture's share of GDP was 38.5 percent, with services accounting for 46.3 percent and industry 15.1 percent. $^{6}$

According to the Ethiopia Demographic and Health Survey (EDHS), ${ }^{7}$ there have been improvements in the country regarding access to education, health and infrastructure. However, despite these improvements, Ethiopia still has relatively low rates of educational enrolment, access to sanitation and attended births, and challenges remain around investment in the health, safety and protection of women and girls. Due to the combined effect of these factors, in 2015 Ethiopia ranked 174th out of 185 countries on the UN Gender Development Index (GDI). The GDI (which is a ratio of female to male Human Development Index values) ${ }^{8}$ measures gender gaps in human development achievements by accounting for disparities between women and men in three basic dimensions of human development - health, knowledge and living standards. Girls and women are at a distinct disadvantage compared with boys and men on a range of issues. According to the EDHS (2014), though there are significant improvements towards access to education for female and male, the gap is still high (48 percent for female and 37 percent for male). And the gender gap is more evident at lower levels of education than at higher levels. ${ }^{9}$

\subsection{The humanitarian context of the current drought}

Ethiopia faces a number of different types of humanitarian situation, including responding to the needs of refugees from different conflicts in the region. However, this report focuses on the current drought, given the extent and severity of the humanitarian situation. A powerful El Niño effect in 2015, combined with the failure of the short rains (belg) and the poor performance of the long rains (kirmit or meher) over the past two years, has resulted in a large-scale drought that has affected several areas of the country. As a result, according to the government, the number of people requiring food assistance increased from 8.2 million in October 2015 (Government inter-agency mid-meher seasonal assessment, November 2015) to 10.2 million in December $2015^{10}$ (in addition to the 8 million people already covered by the Productive Safety Net Programme (PSNP)), ${ }^{11}$ meaning that Ethiopia has the largest acutely food-insecure population in the world. Established in 2005, the PSNP programme of the Ethiopian Minister of Agriculture is aimed at enabling the rural poor facing chronic food insecurity to resist shocks, create assets and become food self-sufficient. Thus, many people - and in particular children and pregnant and lactating women - need emergency food assistance, water, sanitation and hygiene (WASH) services, nutritional support and education and health services. ${ }^{12}$ The pastoral and agro-pastoral areas of Afar, Somali and parts of Oromia and Amhara regions are those worst affected by the drought. 


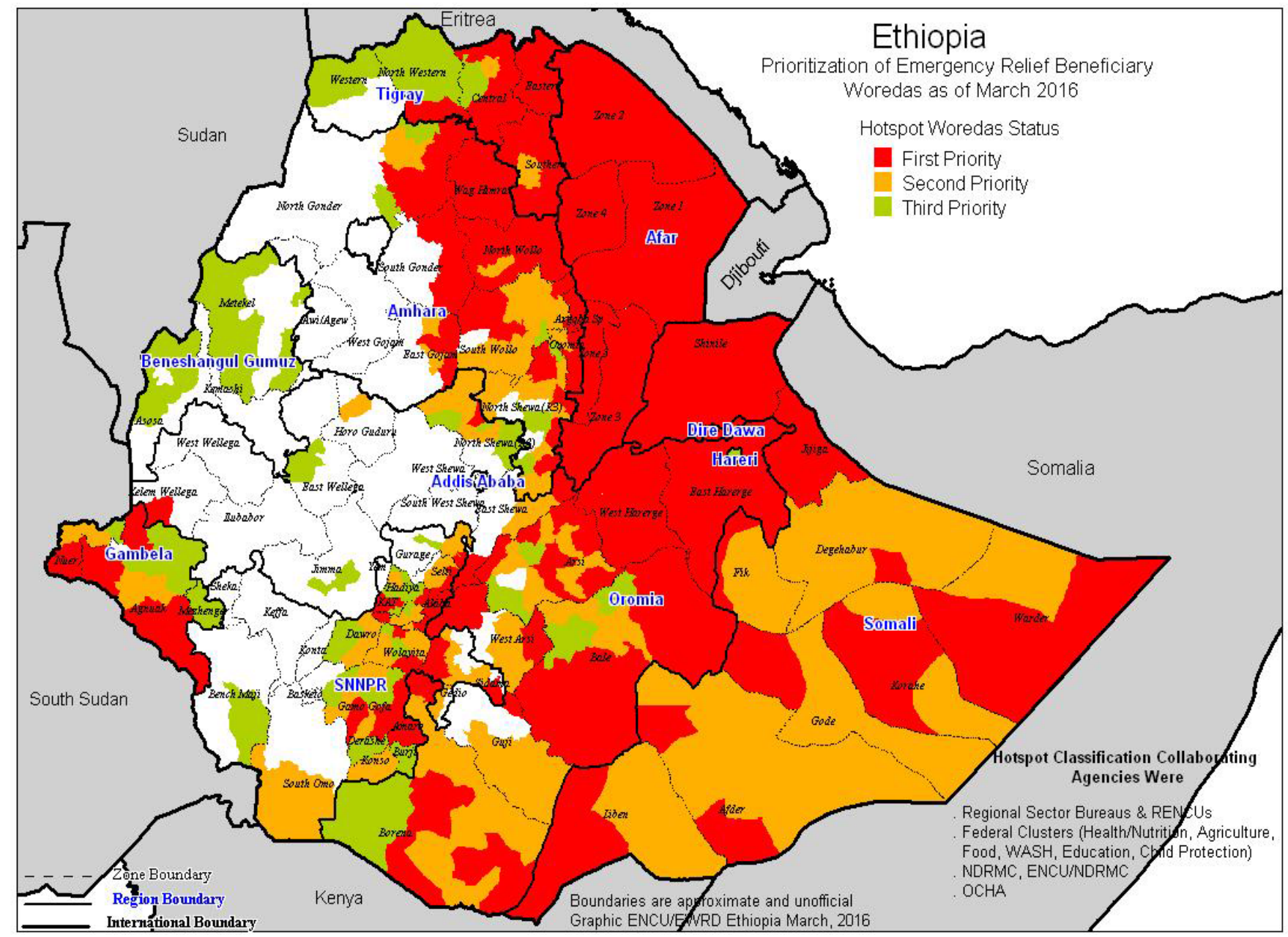

Source: Revised Ethiopia drought strategy document, Oxfam, 2016.

\subsection{Background to this report}

A coordinated effort by humanitarian actors is crucial to mitigate the worst effects of the current drought on men and women, girls and boys. A Gender in Humanitarian Action Working Group was therefore re initiated on this current drought, consisting of eight international and local humanitarian organizations active in Ethiopia (Oxfam, CARE, Concern Worldwide, GOAL, ChildFund, the Consortium of Christian Relief and Development Associations (CCRDA), Sustainable Environment and Development Action (SEDA) and the Rift Valley Children and Women Development Organization (RVCWDO), with the support of the ECHO-funded project 'Gender in Emergencies: Institutionalization of Policy and Practice'. This 18-month-long ECHO-funded project aims to catalyze change within the humanitarian sector by institutionalizing gender mainstreaming in emergencies and strengthening accountability to enable response capacity for adapted assistance to meet the needs of women, girls, boys and men. In this light, the aim of the working group is to create a platform to enhance organizational learning and capacity to mainstream gender in emergencies.

From the working group, CARE Ethiopia conducted a Rapid Gender Analysis and Oxfam conducted a Comprehensive Gender Analysis as part of their respective emergency responses. Both analyses were carried out in March-April 2016. The two organizations used the data collected to inform capacity building and to help the working group set priorities, and compared findings with other relevant information and research. 
This report presents a consolidated set of findings and recommendations from the two gender analyses by the Gender in Humanitarian Action Working Group for the consideration of decision makers and practitioners in national and international humanitarian agencies, as well as the Ethiopian central and regional governments. It aims to bring together learning on the differential impacts of the current drought on women, girls, men and boys in affected communities that could be used to investigate how the crisis may have exacerbated existing vulnerabilities and reinforced gender norms and roles. These findings could be relevant countrywide, and offer practical entry points to enhance a gender-responsive approach to humanitarian action, which will be reflected in the next Humanitarian Requirements Document (HRD) exercise, which is developed by the Government supported by the international humanitarian community, will be due in July-August 2016.

The document is structured into four sections. Section 1 focuses on the gendered impact of the drought and is complemented by Section 2, which explores shifts in gender dynamics as a result of the drought at household and community levels. Section 3 identifies practical entry points for a genderresponsive humanitarian drought response, while Section 4 highlights concrete recommendations for humanitarian actors.

\subsection{Sampling and methodology}

Oxfam's analysis was carried out in five kebeles (sub-districts) in the two regions of Somali (Siti Zone) and Afar (Zone 2), while the CARE research took place in the drought-affected areas of Oromia (East and West Harerge Zones), Amhara (South Gonder Zone) and Afar regions (Zones 1 and 3). In total, the analyses covered 21 kebeles in Somali, Oromia, Amhara and Afar regions; all the woredas (districts) involved are labelled 'hotspot category one' by the Ethiopian government.

A gender-balanced team gathered primary data, with the support of translators. The selection criteria for respondents in both analyses were based on purposeful and targeted sampling to reach the most vulnerable households and to achieve a gender balance among male and female respondents in each kebele. Oxfam also captured specificities of settlements for internally displaced persons (IDPs).

Both gender analyses made use of qualitative focus group discussions (FGDs), while Oxfam additionally applied quantitative surveys and 'kebele observation checklists'. CARE used FGDs with picture codes, and carried out a transect walk for resource mapping. The picture codes allowed women, boys, girls and men to clearly relate to the content of the discussions, and to describe their reality as they lived and remembered it. This tool was applied in FGDs held separately for groups of men, women, boys and girls to help stimulate discussions on how the drought had affected them, how they were facing the situation (coping mechanisms) and what new social norms and opportunities were emerging as a result. The transect walk was used to gather on-site information on what resources, assets, services and infrastructure existed in the community, and how different members of the community accessed and managed them.

The quantitative survey by Oxfam included over 60 questions and was divided into sections covering demographic information, analysis of the gendered division of labour, decision making, access to and control over resources, and humanitarian assistance. The questionnaire was implemented with 179 respondents across the five kebeles. The guiding questionnaire for the FGDs contained questions that probed the gendered impact of the drought, while the kebele observation checklists captured basic living conditions at household and community levels. Before the quantitative survey took place, the data gathering team was given training on gender equality and the use of mobile technology for data collection. 


\section{IMPACT OF THE DROUGHT ON MEN, WOMEN, GIRLS AND BOYS}

\subsection{Access to food and water - overall vulnerability}

According to the Ethiopia Humanitarian Requirements Document, ${ }^{13}$ the drought-induced increase in household food insecurity will result in acute malnutrition. The report shows that currently, 435,000 severely malnourished children across the country are being targeted, as well as one million moderately malnourished children aged 6-59 months and 700,000 moderately malnourished pregnant and lactating women. ${ }^{14}$

In Oxfam's Comprehensive Gender Analysis, from a total of 179 respondents the most food-insecure population groups were felt to be infants, elderly people and pregnant and lactating women. Women as a general category also appeared to be more vulnerable than men.

Figure 2: Perceptions of the most food-insecure population groups in Somali and Afar regions

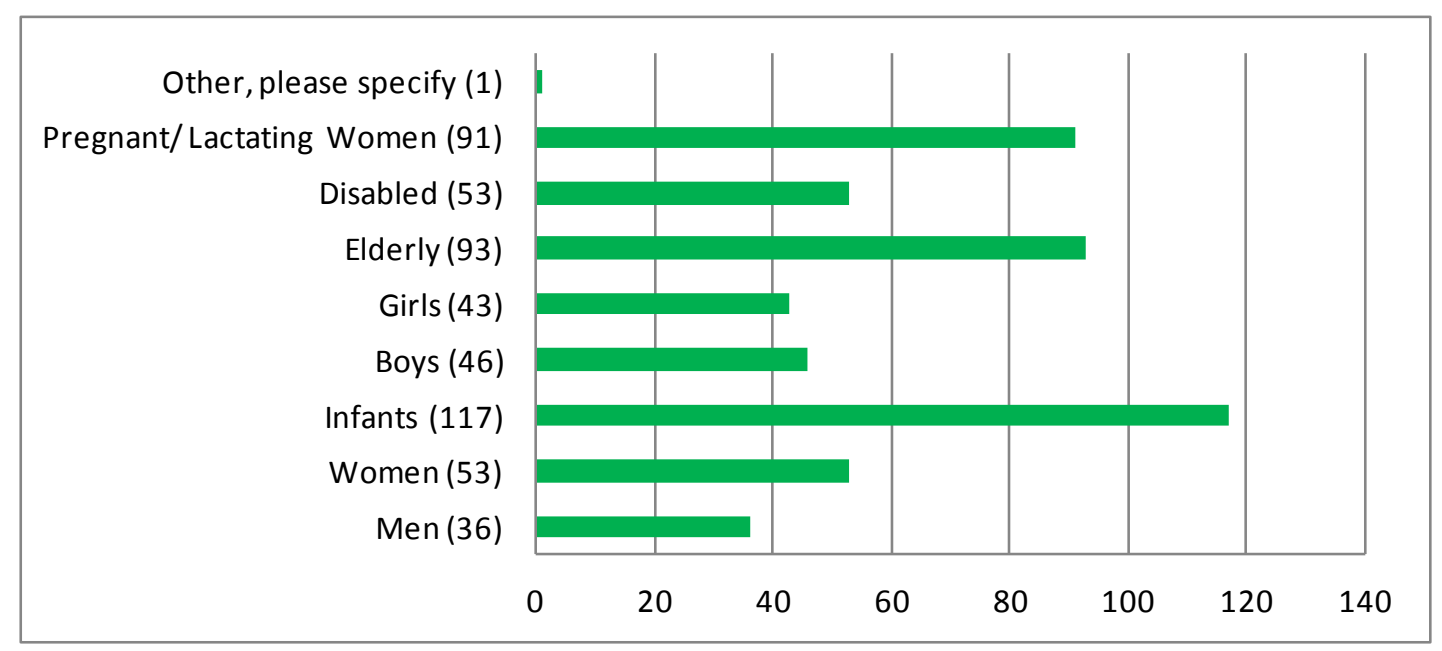

Source: Comprehensive Gender Analysis, Oxfam, March-April, 2016

\section{Vulnerability of infants and children}

From the qualitative data, it appears that food insecurity of infants and children relates to their capacity to digest available food, which they provided with the humanitarian assistance. As one FGD participant said: 'We are given grains, but children cannot eat this grain, as we don't have mills to process food' (FGD, Hadkaley, men). Another difficulty for children, as well as for elderly people, relates to the need to add liquid (milk, oil or water) to the food, which at times is barely available. Women across the different kebeles stressed the lack of nutritious food in sufficient quantity for their children and the consequences of this; in particular, the consequence of 'lack of milk for children is abdominal diseases and loss of weight' (FGD, Asangalo, women). It is common for people to eat only once a day. If food is available, it is prepared in the evening, as during the day children are playing or helping with chores.

This was also found to be the case in almost all the communities studied by CARE, where qualitative FGDs showed that infants depend on their mothers' breast milk or cow's milk as a food source. Infants' chances of experiencing malnutrition have increased because the supply of milk from both their 
mothers and from cattle has decreased; the frequency of breastfeeding may have reduced due to the fact that mothers are not eating enough to produce sufficient milk.

\section{Women de-prioritized for food}

Male and female respondents to the Oxfam survey in Somali and Afar regions referred to restrictions around personal food intake, which included reducing the number of meals per day, eating less preferred or cheaper foods, borrowing food and limiting portion sizes at mealtimes. In the CARE study, findings from East and West Hererge, Afar and South Gonder showed that both the frequency of food consumption and the amount of food intake have reduced; people within the communities were also more likely to eat a single component of a meal (for example, injera (a staple flatbread made from teff flour) without stew, or maize without milk), which increases the chance of malnutrition, particularly among the most vulnerable people.

The perception of infants and children being the most food-insecure groups coincides with responses on who is prioritized for food intake within households in all the areas studied by Oxfam (Figure 3).

\section{Figure 3: Priorities for food intake in households in Somali and Afar regions}

Women respondents

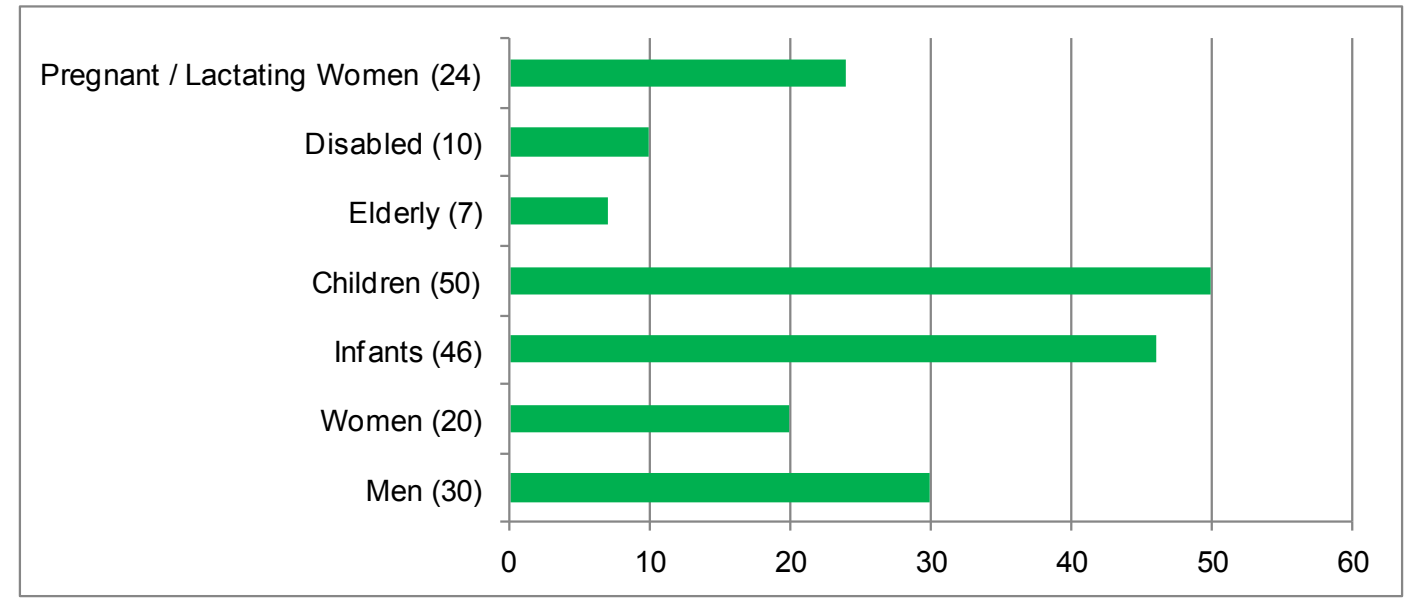

Men respondents

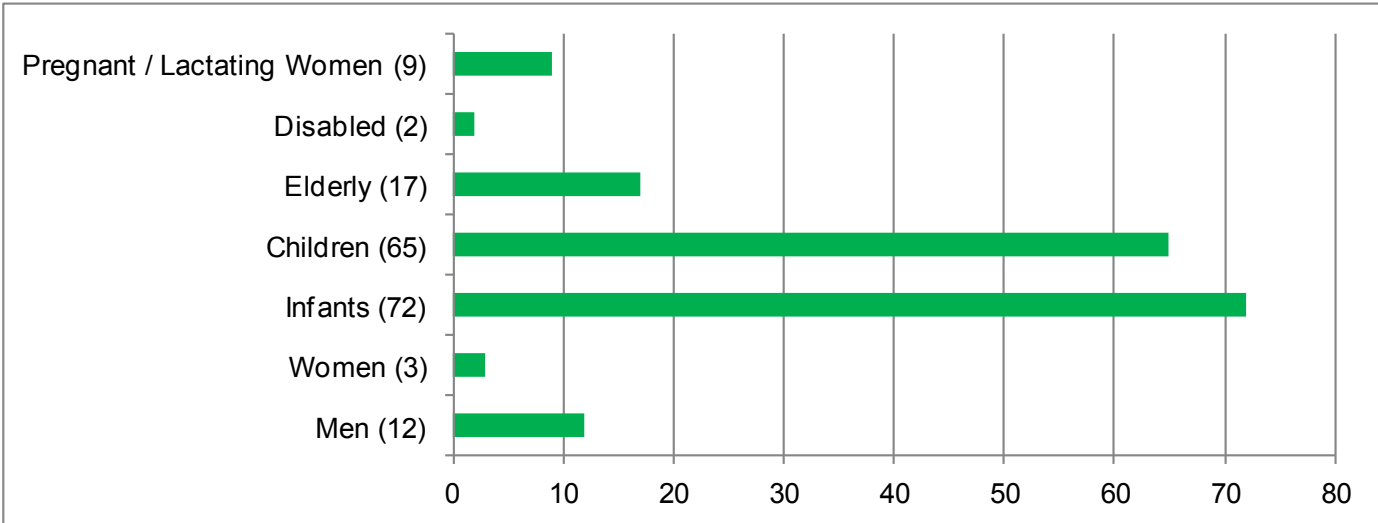

The gender-disaggregated data in Figure 3 show that male respondents reported that higher priority was given to feeding infants and children within the household, while adult women were de-prioritized by men. In contrast, female respondents reported giving adult women some priority, but still lower than that given to men. In areas studied by CARE, communities mentioned that men and children under the age of three ate first in the family, boys and girls next and women last, increasing women's chances of being affected by health problems and malnutrition. 
While there was a general acknowledgment that pregnant and lactating women require sufficient quality and quantity of food, these responses show that pregnant and lactating women are not prioritized for food intake. In addition, qualitative data suggest in some cases that pregnant and lactating women may skip meals so that other household members can eat, while continuing to engage in physically demanding chores (FGD, Hadkaley, men). This finding was backed by the CARE study report in East and West Harerge and South Gonder zones. Oxfam's quantitative survey shows that 41 percent of respondents had a pregnant women living in their household, suggesting that pregnant and lactating women need to be specifically targeted by humanitarian assistance. Furthermore, in some areas such as West Hererge and South Gonder, cultural restrictions prevent women from eating certain food types, such as food prepared from an animal's tongue, brisket, head or hump.

\section{Polygamous households}

In Ethiopia, the practice of polygamy is religiously acceptable in Muslim areas, but not legally recognized. In the context of the drought, polygamous households that share limited humanitarian resources may represent a special category of vulnerability.

In Somali and Afar, 84.4 percent of married respondents live in a monogamous relationship, while 15.6 percent live in a polygamous relationship. Polygamous households are more prevalent in Somali Region, although FGD participants in other regions also referred to the specific challenges of polygamy (FGDs, Galaiso and Asangalo). It appears that polygamous households face disproportionate vulnerability, as humanitarian assistance is provided for a single household (especially if provided only to the husband) but may be split between approximately three families (given that 22 of the 24 respondents living in polygamous relationships reported living with three cowives). Depending on local practices, the shares that co-wives receive are largely at the discretion of the husband: 'In polygamous households, the distribution of resources between women and men is not fair - men are the decision makers' (FGD, Galaiso, women). The extent to which co-wives collaborate differs across the kebeles analyzed. In Asbuli kebele, the study observed the practice of wives claiming non-food item (NFI) kits for their co-wives (who were fetching water at the time of the distribution), while in other instances women reported sharing income from cash-for-work (CFW) activities with their co-wives, at the request of their husbands (FGD, Asangalo, men).

The CARE study findings reveal that women who live in polygamous families in Afar and East and West Harerge are most vulnerable, since their lives depend on the favour of their husbands - and husbands tend to share the limited resources they can access during the drought with the family they favour the most.

\section{Female-headed households and women at sub-kebele level}

A somewhat different aspect of vulnerability based on movement restrictions relates to households, often female-headed, who live at a distance from distribution points for humanitarian assistance. 'The most destitute are left behind in the hills; they really need urgent evacuation' (FGD, Hadkaley, men). These households lack reliable information about the distribution of humanitarian assistance, or cannot travel to the kebeles for registration and distribution due to loss of their livestock, which means they lack a means of transport. In East and West Harerge, Afar and South Gonder, female-headed households are also more affected than male-headed households because they carry the entire burden of supporting the family, yet they cannot travel far away in search of jobs.

In male-headed households, while women take care of household tasks, the men go out to look for work and food. This means that men may have access to food outside their homes, while women and children may not have access to food at home and may have to wait for the man to bring them something to eat. 


\section{Other reasons for food security and overall vulnerability}

Elderly females ( $>59$ years of age) and disabled people were identified as being vulnerable, as they are increasingly dependent on other household members as traditional support mechanisms are reduced. 'Disabled individuals used to get help from pastoralists in gift and credit (zakat), but now there is no livestock, so there is no longer zakat to pay' (FGD, Hadkaley, men).

\subsection{Livelihoods and access to productive land}

Protecting and restoring livelihoods is one of the main strategic objectives of the humanitarian response plan (Ethiopia HRD, 2016) ${ }^{15}$ since the drought has destroyed livelihoods as a result of poor health and livestock death, or has made them insecure due to limited access to seeds and other agricultural inputs for the coming year. The HRD focuses on priority woredas to ensure that precarious livelihoods are protected by taking advantage of the 2016 rains and through provision of timely access to seeds, fertilizer and livestock support, including plough oxen, fodder, access to drinking water and livestock vaccination.

FGD participants in the Oxfam study in Somali and Afar reported that the current drought has affected the livelihoods of the community in various ways. In all regions the drought has affected the productivity of the land and water sources and pastures, such that agricultural output is limited, water points have dried up and forage has not regenerated. This affects the livelihood of every member of the community (men, women, boys and girls) in different ways and to varying degrees. Quantitative data suggest that there are no significant gendered differences in terms of drought-specific impacts on livelihoods, which are loss of livestock, reduction of income and an increase in debt (see Figure 4).

Figure 4: Oxfam survey data on how livelihoods have been affected by the drought, among 179 respondents

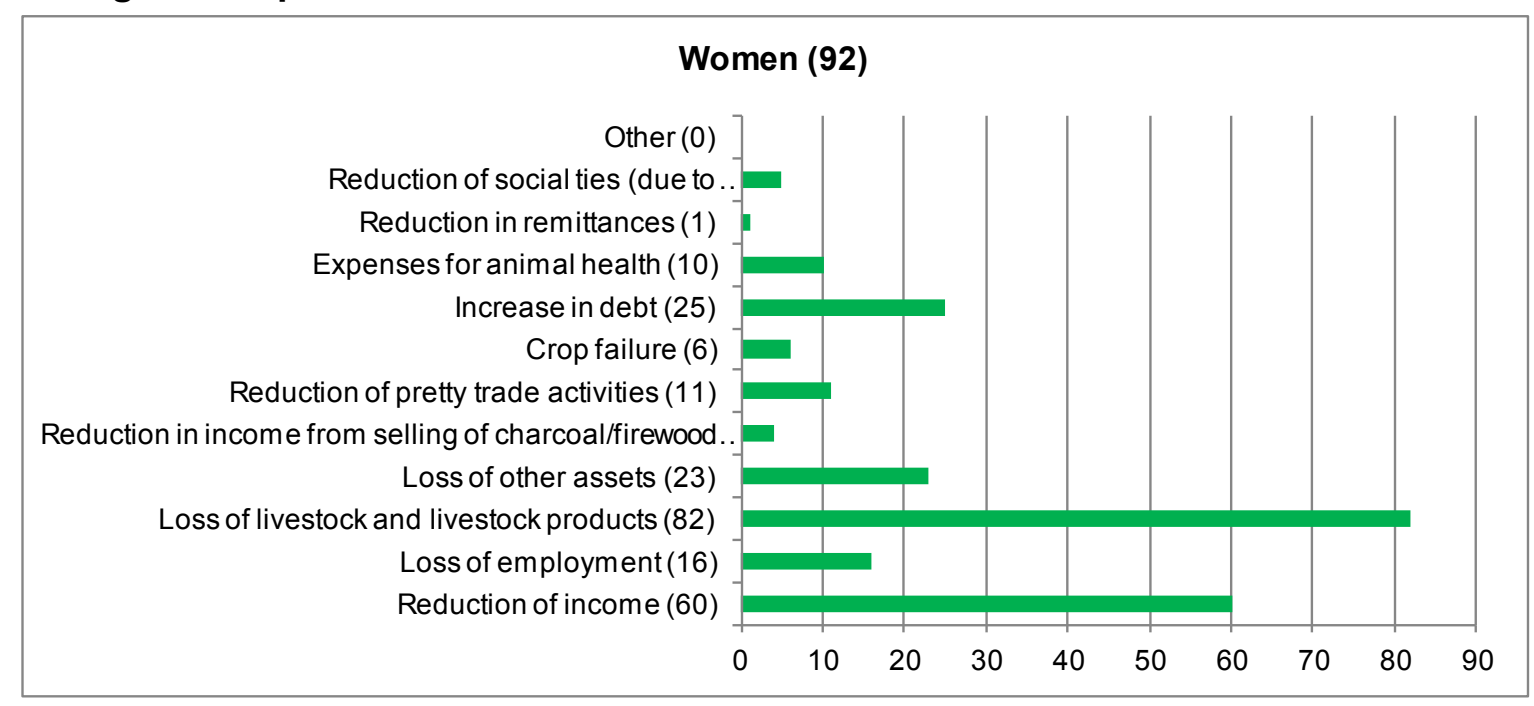




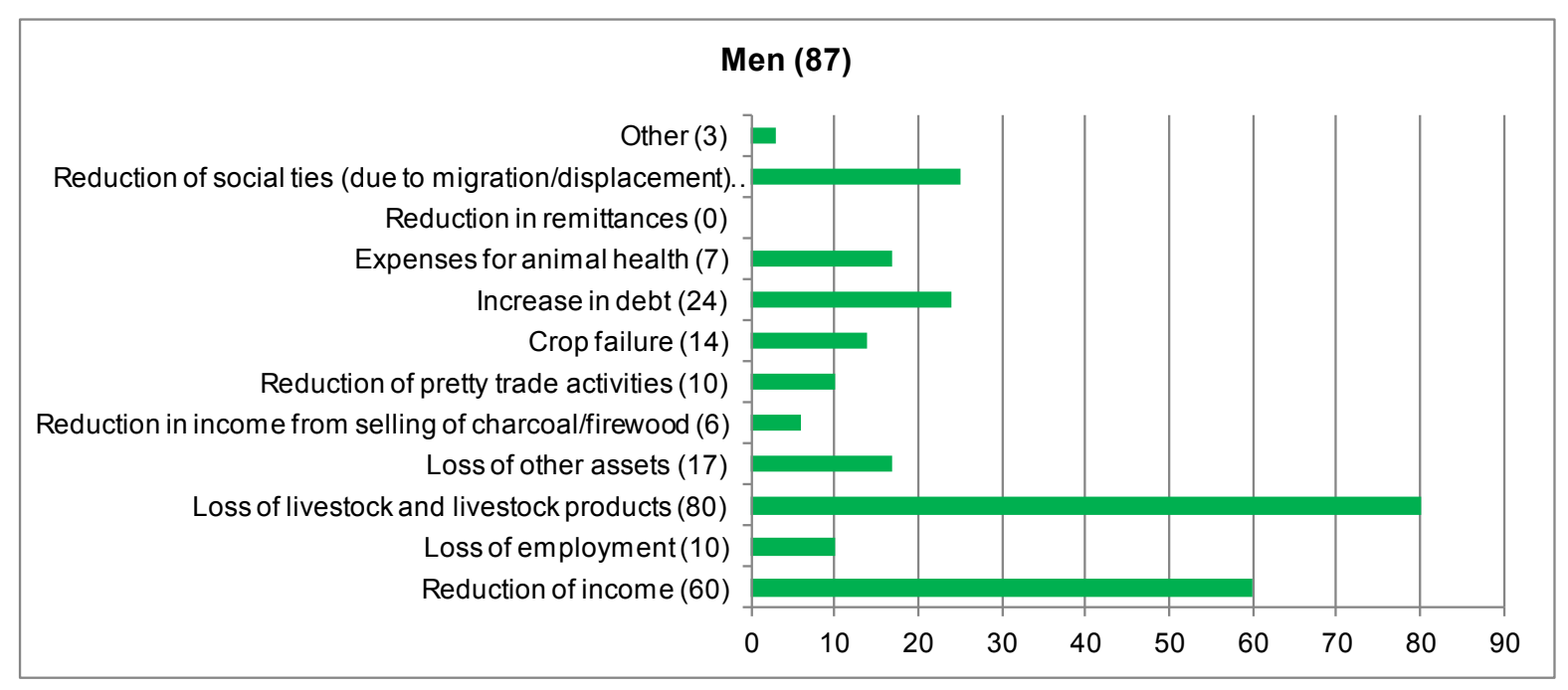

\section{Loss of livestock}

The most significant impact of the drought on livelihoods in Somali and Afar regions is loss of livestock. For example, in Hadkaley kebele (Siti Zone) 90 percent of respondents, in Galaiso kebele (Zone 2) 100 percent of respondents and in Asangalo kebele (Zone 2) 98 percent of respondents reported loss of livestock as having the biggest impact on their livelihoods. Loss of livestock affects pastoralist households disproportionately in comparison with agro-pastoralist households: 'The drought affects farmers, but their land remains to yield output in the next season - but for us pastoralists, we are the most destitute, even if it rains now' (FGD, Hadkaley, men). Pastoralists lack alternative coping mechanisms: 'Agro-pastoralists can resort to feeding their animals crop residue and fodder, but landless pastoralists have nothing to feed their animals' (FGD, Arabi, men).

While the loss of livestock disproportionately affects men as the main owners of livestock (in particular pack animals), women's access to livestock products for household consumption, such as milk, butter and meat, has significantly diminished. In consequence, women have also lost access to income from selling milk products, over which they had relatively independent decision-making power before the drought. With limited money in circulation, petty traders, who are mostly women, have been forced to cease or significantly reduce their business activity.

\section{Low agricultural production}

In Ethiopia, 80-85 percent of the population practise rain-fed agriculture. After a decade of impressive increases in annual agricultural production and productivity, the 2015 cropping season was poor. The failed belg rains not only resulted in a failed belg harvest, but also prevented smallholder farmers in the belg and kirmit rainfall areas from planting longer-maturing crops such as maize and sorghum (Ethiopia HRD, 2016). ${ }^{16}$

In the Oxfam study, despite the perception that agro-pastoralists are better off, quantitative data show that farming activities have been significantly reduced, and the loss of livestock has also been high amongst agro-pastoralists.

The CARE study in East Harerge shows that the drought has also seriously affected people whose livelihoods are dependent on agriculture. Land and water sources and pasture are severely affected. In West Harerge, agricultural production and productivity have been low, crops have dried up in the fields and cattle are dying due to shortages of fodder and water. In South Gondar, there is a shortage of water and feed, and the land has become dry. Production of sorghum, teff, beans, chickpeas and other crops has been affected. Cattle are also suffering from lack of feed and water. In order to save 
their livestock, men and boys are forced to migrate to neighbouring woredas and kebeles where there are better pasture and water.

\section{Reduction of income}

With the loss of livestock products, women cannot engage in market activities: 'Before the drought, we were selling milk, butter, meat and livestock to cooperatives, and we were buying everything including food for household consumption, but now there is nothing to be sold' (FGD, Asbuli, women).

The reduction of income affects women disproportionately, as they are exclusively in charge of traditional milk processing and selling at the markets, and in turn use the income they earn to buy the most preferred food for household consumption. The majority of petty traders are also female: 'Some shops have had to close because their stock is finished - even if there was something to sell, there is no one who can buy' (FGD, Asbuli, women). A breakdown by region shows that in Somali 70 percent of respondents in Hadkaley and 80 percent of those in Arabi Kebeles reported a reduction of income, while 74 percent of respondents in Afar, Galaiso kebele (Zone 2) and 58 percent in Asangalo kebele (Zone 2) reported the same. In the CARE study, similar findings in the South Gonder FGD suggest that female-headed households that engage in petty trade such as selling tella (a local alcoholic drink) are unable to sustain their businesses because of their responsibilities for managing their households. They are also unable to migrate to different areas, either because they fear leaving their own area or because travelling alone has become more stressful.

\subsection{Access to education}

The education system is heavily impacted when flooding destroys schools (in regions such as Afar and Somali) and droughts force families to abandon their homes in search of food, water and protection. The loss of assets and livelihoods has compromised the capacity of parents and care givers to send their children to school, leaving them unable to cover costs of clothing, school materials and food (Ethiopia HRD, 2016). ${ }^{17}$ The HRD also shows that schools in drought-affected regions have closed due to pastoralists moving with their children in search of water and pasture. Moreover, in almost all affected schools, high levels of absenteeism have been observed as children are expected to assist parents, while inadequate food intake limits their capacity to stay in class and affects their attention levels.

Increasingly, more girls than boys are absent from school, as they are spending more time on domestic responsibilities such as walking long distances to fetch water, caring for younger siblings at home and trying to generate income. According to CARE's findings, in Afar and Oromia regions (East and West Harerge Zones), boys and girls are dropping out of school due to lack of school materials. Boys travel long distances to search for pasture and water for livestock, or migrate to other towns to find work as daily labourers.

\subsection{Health, including sexual and reproductive health}

Estimates in the HRD (2016) show that poor water availability, lack of sanitation, decreased food availability and displacement are factors that will significantly heighten the risks of increased mortality and morbidity, including from malnutrition and outbreaks of communicable diseases such as measles, meningitis, malaria, dengue fever, Acute Watery diarrhoea and acute respiratory infection. It is estimated that 20 percent of the expected 435,000 severely malnourished children will develop medical complications that will require intensive, life-saving medical treatments in hospital-based therapeutic feeding centres. Malnutrition amongst pregnant women increases the risk of abortion, foetal death and bleeding, contributing to increased maternal and neonatal morbidity and mortality. A minimum initial sexual and reproductive health service package is required. Stresses due to 
displacement are also linked with increasing psychosocial and mental health effects. Overburdened national health systems will face increasing difficulties in addressing emergency health needs.

The study by CARE shows that the community is vulnerable to sanitation-related health problems. This risk is exacerbated by water scarcity, pollution and contamination. In East and West Harerge, Afar and South Gonder, the lack of safe, clean water is causing health problems, particularly diarrhoea. During the assessment period of the CARE analysis, there were a few cases of measles in Afar, which the community was not equipped to treat. At the same time, the dustier environment caused by the drought generates airborne diseases, while in South Gonder the community is vulnerable to waterborne diseases.

\subsection{Access to WASH}

The national level of access to water in Ethiopia is 61.6 percent, with 66.3 percent in rural areas and 82.4 percent in urban areas in $2012 / 13 .^{18}$

\section{Latrines and bathing facilities}

In the Oxfam study, open defecation was prevalent in all kebeles analysed in Somali and Afar. Some 69 percent of all respondents do not use latrines. While more respondents report latrine use in Siti Zone (40 percent) than in Zone 2, there is no significant difference between women's and men's latrine use.

\section{Figure 5: Use of latrines in Siti Zone and Zone 2}

\section{Siti Zone: Women (49)}

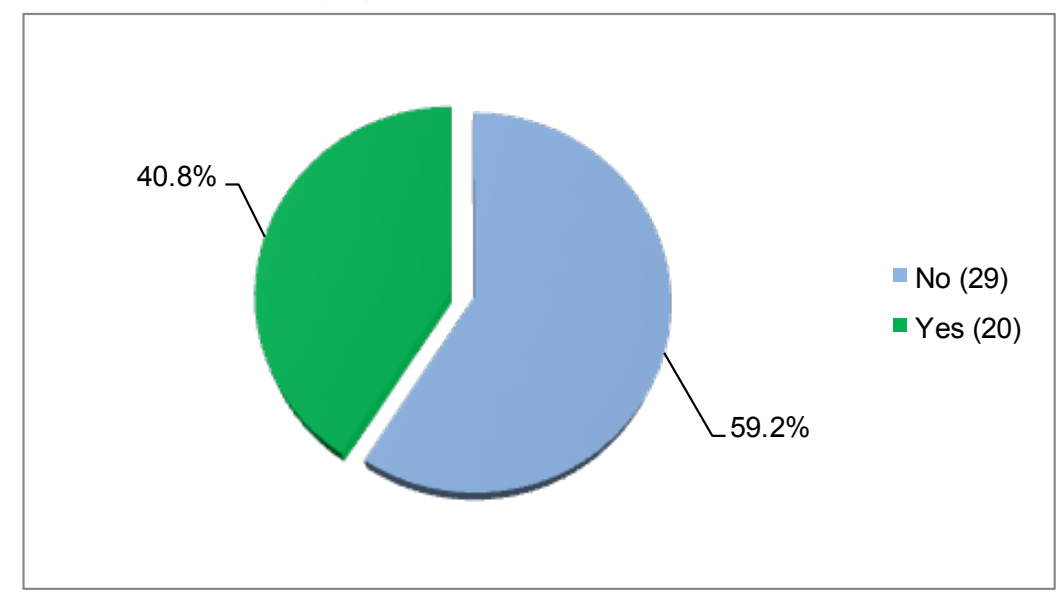

Siti Zone: Men (45)

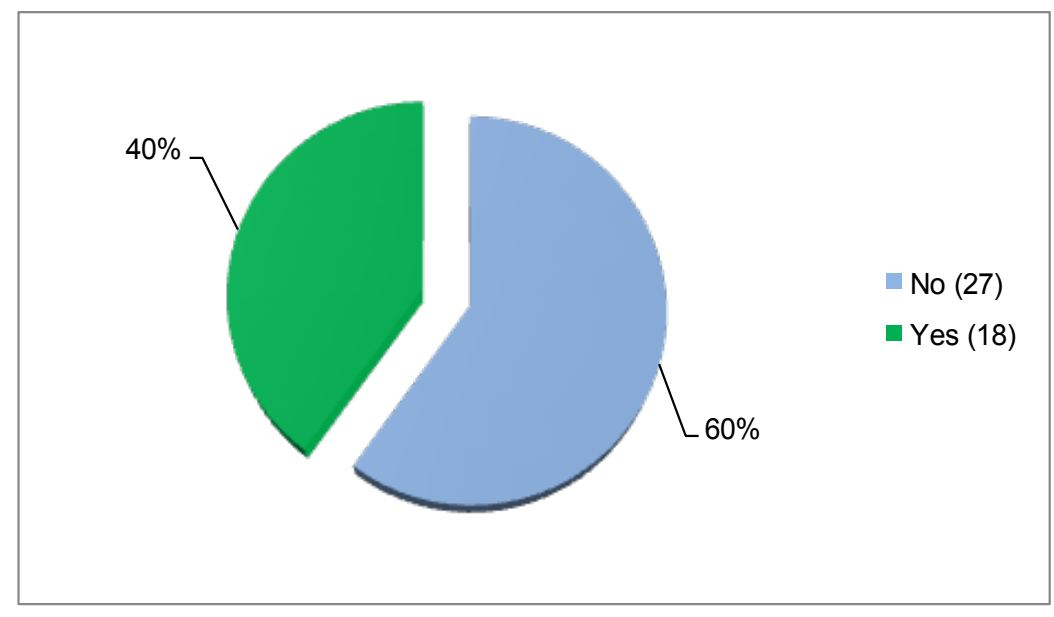




\section{Zone 2: Women (43)}

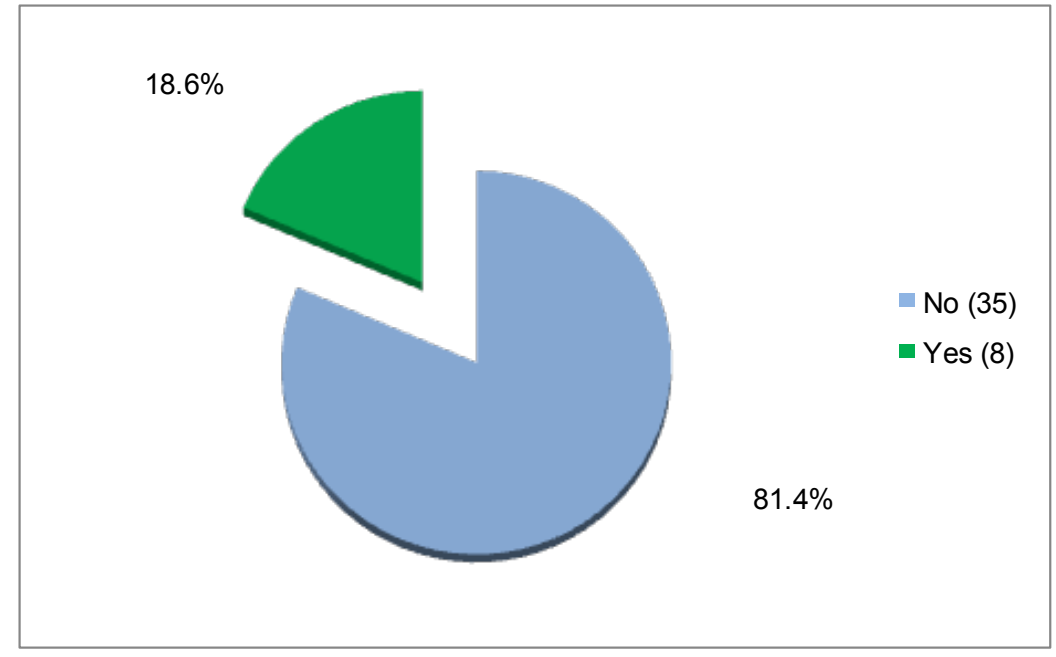

Zone 2: Men (42)

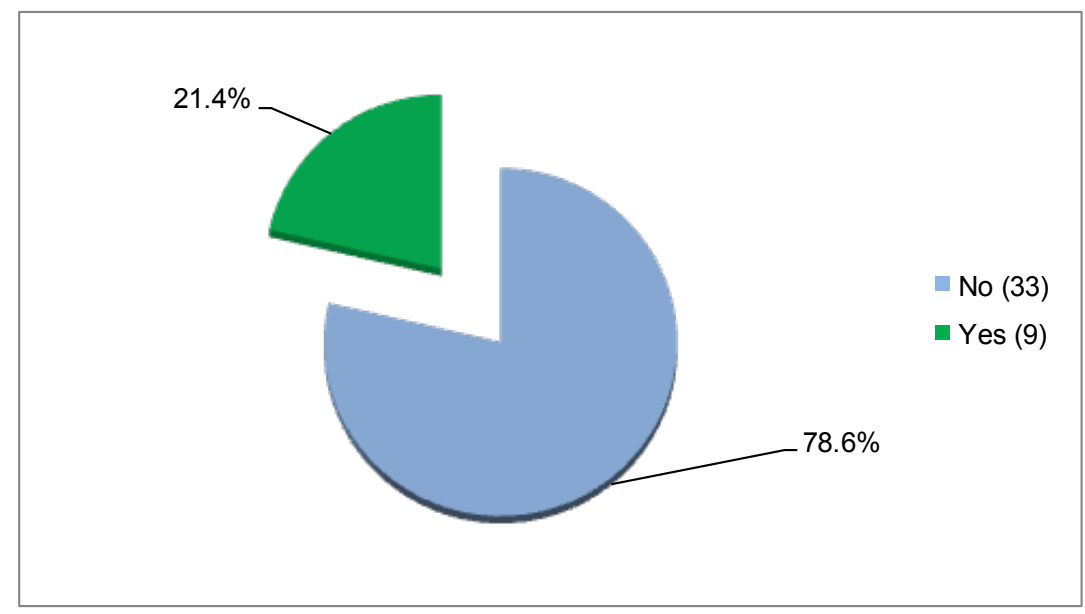

The main reason given for not using latrines is their unavailability (69 percent). 'We don't use latrines but prefer open defecation, because there are not enough latrines' (FGD, Hadkaley, women). Of the 55 respondents ( 28 female and 27 male) who had access to latrines, 60 percent used private latrines, while 40 percent used communal/public latrines. Of a total of 28 female respondents, comparatively more women used private and household latrines (63 percent) than communal latrines (37 percent).

\section{Hand washing practices}

Proper hand washing is one of the simplest and most effective means of preventing the spread of infections such as diarrhoea. Generally speaking, hand washing among men and women is influenced by different factors such as access to water and personal attitudes. Regarding hand washing practices, 77 percent of respondents replied that they did practice hand washing, while 23 percent reported that they only washed their hands sometimes. Among IDPs, hand-washing practices were less prevalent (61 percent), while 39 percent sometimes washed their hands. Women reported a higher level of hand washing than men: 89 percent of women reported that they washed their hands regularly, but only 63 percent of men reported the same. Some 87 percent of respondents reported using only water while significantly fewer respondents, 18 percent, used water with soap. Among the IDP population, none of the respondents washed their hands with soap. Applying a genderdisaggregated lens, among all women who wash their hands, 83 percent reported that they used water only, while 17 percent of women washed their hands with water and soap, significantly higher than the 
12 percent of male respondents who did the same. There was no significant variation between the responses from Somali and Afar regions. Menstrual hygiene

In terms of menstrual hygiene, 58 percent of female respondents reported using reusable cloths, followed by 28 percent who only used washing facilities, while 17 percent reported not using any means of menstrual hygiene. No significant changes in practices before and during the drought were reported. In terms of access to menstrual hygiene materials, 72 percent of respondents reported making cloth pads themselves, while 18 percent did not use any menstrual hygiene means and only 5 percent relied on distributions from humanitarian agencies. Also, 78 percent reported reusing menstrual hygiene materials, while 8 percent disposed of menstrual hygiene materials after use.

\subsection{Access to information}

Both Oxfam's and CARE's humanitarian assistance for the communities in the study areas includes the distribution of NFIs and seeds, water provision, cash distribution, food distribution, hygiene promotion, livestock health and destocking. Gender-disaggregated analysis of how beneficiaries access information on humanitarian assistance suggests that 59 percent of women obtain relevant information from neighbours, while 37 percent rely on information from the market place. In contrast, 56 percent of men access information through neighbours, 37 percent from NGOs and 26 percent from the mosque.

Communities who live some distance from the distribution centres in Somali and Afar regions, especially female-headed households at sub-kebele level, lack reliable information about registration for and distribution of humanitarian assistance.

\subsection{Protection issues}

According to the HRD document, children are exposed to protection issues such as child labour, trafficking and exploitation because of closed schools and increased absenteeism (Ethiopia HRD, 2016). ${ }^{19}$ Women and adolescent girls are also affected, and are exposed to different kinds of protection issues such as rape, early and forced marriage, physical violence and beating by other household members. In an internal protection analysis by Oxfam (Sasvari, 2016), ${ }^{20}$ IDP women in Hadkaley kebele (in Siti Zone) reported cases of rape and of being attacked by strangers while collecting firewood. Pastoralist boys in Ab'ala woreda of Afar region are at risk of physical attacks as a result of conflict over pasture. Furthermore, in areas studied by CARE, women, girls and small children are also particularly vulnerable to attacks by wild animals such as hyenas. These and other protection issues revealed by the studies are discussed below.

\section{Increase of conflict over scarce resources and risk to pastoralist boys in particular}

In the particular context of Ab'ala woreda in Afar Region, female and male respondents in the Oxfam study raised the protection risk for pastoralist boys (14-20 years), who face physical attacks as they are encouraged to go further and further away from their home kebele with the remaining livestock in search of pasture. FGD participants agreed that the drought had exacerbated conflict over pasture, which was not as prevalent before the drought. Some 65 percent of respondents in Afar reported an increase in attacks when travelling outside the community: 'Now there are instances where boys are attacked by men from other neighbourhoods (kebeles or woredas)' (FGD, Asangalo, men).

The CARE study also shows an increase in conflict and theft. People are stealing cattle and teff, and fighting over limited resources including pasture and water. In Afar, male FGD participants said: 'For the sake of our livestock, we are forced to migrate to the neighbouring woreda or kebele where good pasture and water are available. Therefore, we encountered conflict with the communities we compete with for resources. Our cattle were looted by some community members who are not happy about our 
migration to their area. This happened when we went to the Amhara Region, the special zone of Caffa in Oromia Region or the Woladi area.'

\section{Sexual and gender-based violence}

While incidents of sexual violence do not appear to be widespread, the humanitarian community needs to pay closer attention to changing patterns, as factors that allow for increased levels of sexual and gender-based violence (SGBV) are present in the communities visited. These include the need for women to leave the home kebele in search of water, longer waiting times at water points, limited availability of latrines and insufficient lighting. In the CARE study in Afar, the most worrying practice mentioned was mira, whereby it is seen as normal in communities for men to come into women's homes when their husbands are away and to rape/have sex with them. With more men migrating, the prevalence of this practice is expected to increase, and it is a concerning form of SGBV.

\section{Domestic and community-level conflict}

Among all respondents, 62 percent stated that domestic conflict at the houshold level related to decisions about the use of money -59 percent of female respondents and 66 percent of men. The second most prevalent source of tension for men ( 23 percent) related to women engaging in culturally 'inappropriate' roles, while women's second most prevalent source of tension (18 percent) was restriction of movement.

\section{Figure 6: What are the main reasons for tensions within the household?}

\section{Women (92)}

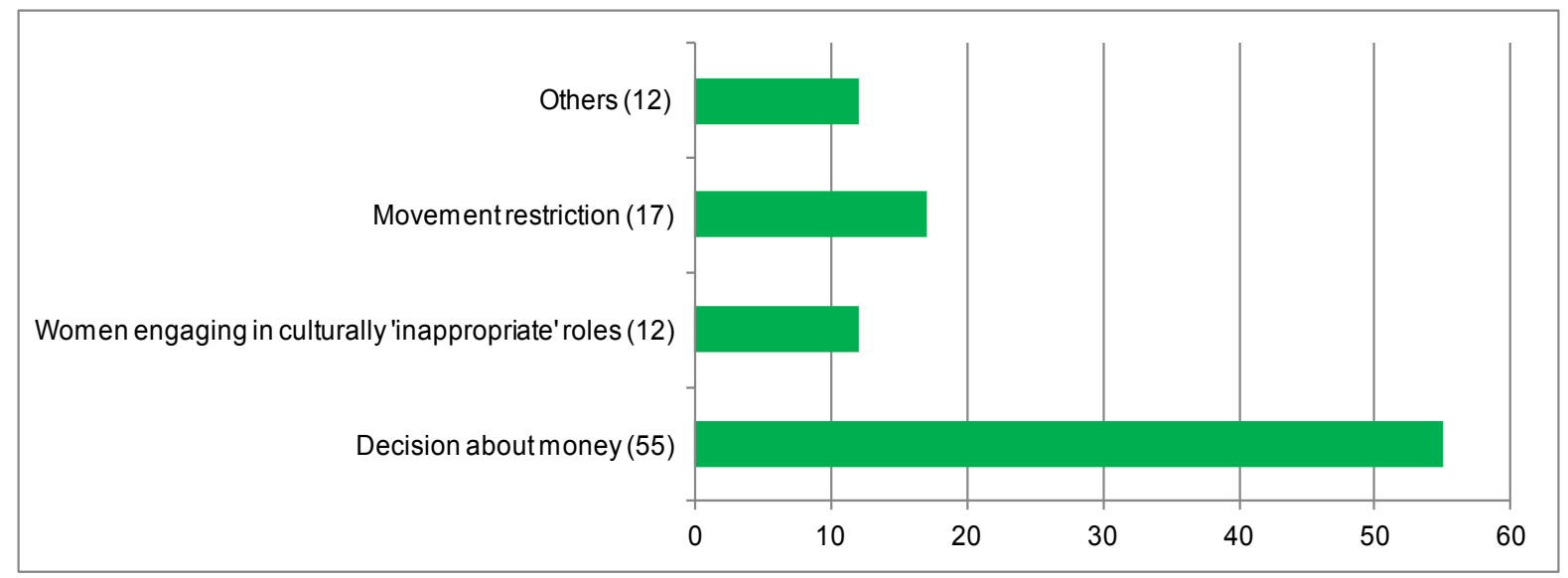

Men (87)

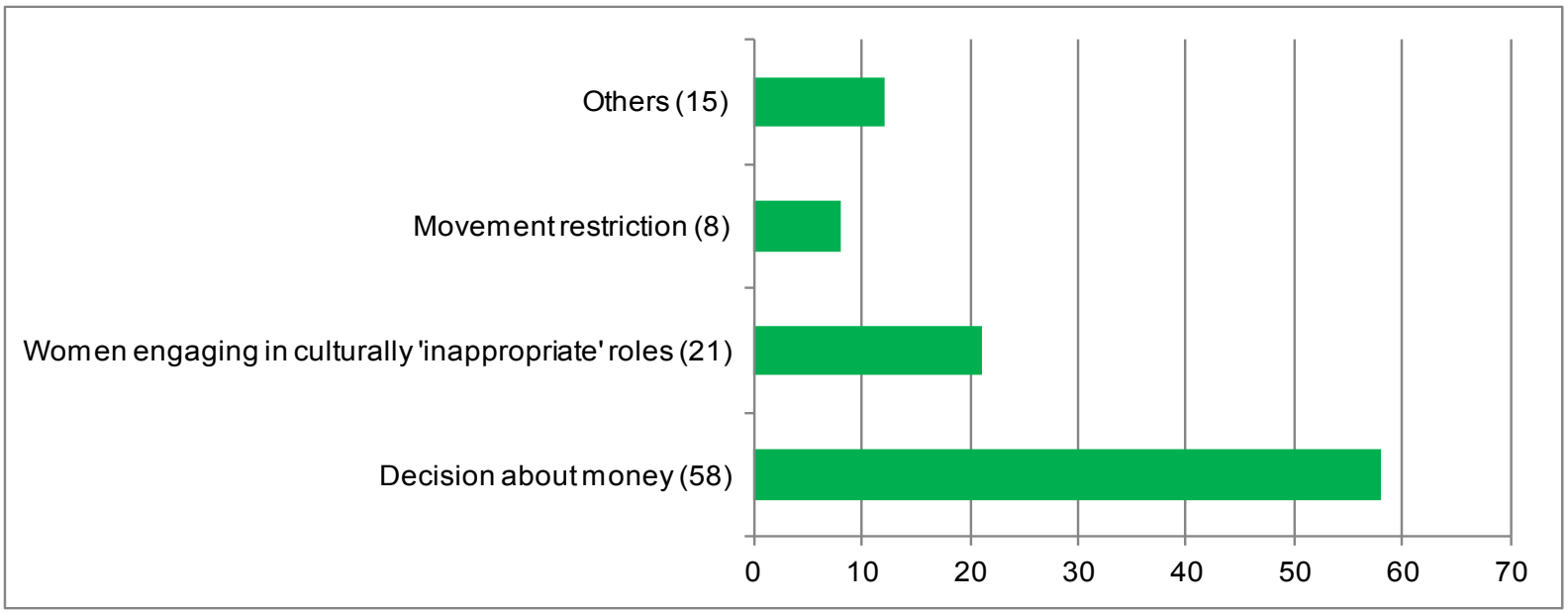


Tensions around the spending of money were particularly prevalent in Afar Region. FGD participants here acknowledged that the drought has increased tension and verbal violence in the household (FGD, Asangalo, women). This relates to scarcity of resources and the fact that women are now more involved in how money is spent. At the same time, men come under considerable pressure from increased debt burden: 'There is growing tension among some households who borrowed money and could not pay it back' (FGD, Asangalo, men). FGD members stressed that tension manifests itself in verbal rather than physical violence: 'There are some verbal conflicts, but it all boils down to awuf awufu. ${ }^{21}$ They ask for forgiveness, and any conflict is gone' (FGD, Asangalo, men).

In both Afar and Somali regions, there is an emphasis on local conflict resolution mechanisms: 'If there is any violence against women in the household, they seek support from elders and religious leaders' (FGD, Asangalo, women). Family members and community leaders resolve domestic conflicts emerged due to the drought, but are limited. Amongst all respondents, 65 percent said that before the drought household tensions were resolved by family members, followed by 52 percent who said that they would be resolved by community leaders. There seems to be only limited reliance on government structures such as the Police or Justice offices.

\section{Migration of adolescent girls as domestic workers}

The increasing number of drought-affected adolescent girls migrating abroad raises further protection concerns. First, they must undertake a long journey to reach their destination: 'Girls walk a long distance to Djibouti, which takes several nights' (FGD, Arabi, men); and they then risk falling into the hands of child traffickers. They are also vulnerable due to being in Djibouti illegally, and many face harsh conditions and exploitation when they find a place of employment.

\section{Trends of early marriage}

It seems from the Oxfam study that the drought has resulted in a decrease in the practice of early marriage, specially in Somali Region; 40 percent of respondents here argued that early marriage was not an issue now, while 39 percent said that there had been a decrease in this practice. In Somali culture, a man is ecpected to pay a minimum of 15 camels or 50 sheep as a dowry to the family of his bride, but because men can no longer afford this, both early and adult marriages have decreased. 'There is no marriage at all now, even adult marriages have decreased. Because of the drought we all are the same now - no one is better in the economy' (FGD, Asbuli, women and men).

Due to the loss of livelihoods, the decrease in early marriage is particularly evident among IDPs in Siti Zone, where 45 percent of respondents reported a decrease, while 45 percent reported that it was not an issue. Out of 146 host community respondents, 33 percent reported an increase in early marriage, while 26 percent reported that the rate had stayed the same. In contrast, in Ab'ala woreda in Afar Region, despite the fact that dowries have decreased and there are no resources for festivities, there are reports of households resorting to early marriage to reduce intra-household resource competition.

Quantitative data support this claim, as 54 percent of respondents reported an increase in early marriage, while 28 percent said that it was the same as before. In Asangalo kebele, a male FGD participant explained that he had decided to marry off his under-age daughter to avoid having to feed an additional household member: 'I have given my daughter to a man residing in the same village, just for the sake of reducing my burden. Her new husband is in the same situation as us' (FGD, Asangalo, men).

The prevalence of early marriage during the drought was also reported by a young man as follows: 'If income-generating opportunities were facilitated, we would not be forced to marry at a premature age and become fathers, and also our young wives would not have to give birth at an early age' (FGD, Asangola, men). The consequences of early marriage, especially for adolescent girls (who are not yet 
physically mature), are acknowledged: 'Due to the impact of early marriage there have been some very young girls that died during delivery' (FGD, Asangola, men).

Likewise, early and child marriage is practised in all the areas studied by CARE, although there is no evidence of it having been exacerbated (or reduced) by the drought. In South Gonder, the findings show that child/early marriage is still being practised, though without the wedding ceremony. In this light, it is necessary to address this issue by protecting girls against the child and early marriage practice.

\section{Prevalence of female genital mutilation/cutting}

Female genital mutilation/cutting (FGM/C) comprises all procedures that involve partial or total removal of the external female genitalia or other injury to the female genital organs for non-medical reasons. ${ }^{22}$ In every society in which it is practised, FGM is a manifestation of gender inequality that is deeply entrenched in social, economic and political structures. ${ }^{23}$ Though its prevalence is decreasing, it is still practised in areas such as Afar, Tigray and Somali. ${ }^{24}$

In the gender analyses, quantitative data indicate a decrease in FGM/C practices due to the drought; however, there are only limited indications that a larger societal transformation in ending this practice is under way. The three kebeles in Somali Region reported a decrease of avergae 62.8 percent in $\mathrm{FGM} / \mathrm{C}$, the main reason being that, 'Circumcision results in a lot of bleeding and our girls do not have enough energy, so we stopped this practice until we get out of this drought' (FGD, Asbuli, women). The decrease in FGM/C practices is significantly higher among IDP respondents, with 75.8 percent reporting a decrease, in comparison with 32.9 percent of host community respondents. In contrast, in Afar Region 70.7 percent of respondents reported that FGM/C practices were continuing despite the drought. Quantitative data contradict qualitative findings, with repondents stressing: ' $F G M$ is prohibited by law. If anyone in our community practises it, we get punished' (FGD, Asangalo, men). This inconsistency suggests that respondents do know about the government's ban on FGM/C, but still do not comply in practice.

\section{Psychosocial effects}

Another element identified in the course of Oxfam's FGDs was dependency on humanitarian assistance provided by the government and NGOs: 'We lost everything. We don't work, we just stay at home - just waiting for help from government and any humanitarian organization' (FGD, Asbuli, men). 'We don't do anything to deal with the difficulty brought by the drought, we just wait for what NGOs give us; thanks to Allah, the NGOs give us wheat, maize, rice, milk. We survive because of them' (FGD, Hadkaley, women). 'If you break your leg, you may still survive, but if your spine is broken you can only wait until you die - our backs are broken' (FGD, Hadkaley, men).

Though the psychological effects of the drought on both men and women are severe, this research mainly identified significant negative psychological effects on men, who feel that they are no longer able to perform their societal role as providers for their families: 'They [men] are demoralized and sit under shades without jobs' (FGD, Asbuli, men), and men 'feel helpless' (FGD, Hadkaley, women). Reports of depression among men emerged in all the kebeles assessed, while in Arabi and Hadkaley kebeles, references were also made to incidents of self-harm among men: 'One man cut off his penis saying that "it should not produce other children I cannot help"' (FGD, Arabi, men). In Hadkaley there were reports of suicide, as men cannot stand 'seeing their children die because of hunger; they prefer to die [themselves]' (FGD, Hadkaley, women). Also, in Hadkaley and Arabi kebeles, participants talked about care givers abandoning their children, as they cannot provide food: 'The community is now taking care of these children' (FGD, Arabi, women). 
Thoughts of an uncertain future also affect pastoralist households, who realize that they cannot return to their preferred livelihood option: 'The biggest challenge to settling permanently is that people don't know any other work. Pastoralists want to continue to engage in livestock herding as usual, but they do not know how' (FGD, Asbuli, men). 'Previously, it was easy for us to work doing what we know, herding, but now we don't know how to work here. Even if it rains, we don't know how to produce food from soil' (FGD, Asbuli, men). One man said: 'If they show us an alternative, we will do it' (FGD, Asbuli, men); this suggests that training in new livelihood options would be appropriate.

\subsection{Decision making and leadership}

Because of the patriarchal society that keeps women in a subordinate position in Ethiopia, women exercise limited decision-making power at household and community levels. This is further exacerbated by their limited access to education, training and employment opportunities.

Analysis of primary data from the Oxfam study indicates male-dominated decision-making patterns at household and community levels. A first set of questions relating to decisions around money within the household ${ }^{25}$ showed most women to have 'no involvement', followed by being 'joint decision makers'. In contrast, most male respondents considered themselves to be 'decision makers', followed by 'joint decision makers'. Female responses about the drought's impact on women's and men's decisionmaking power were largely inconclusive, with equal proportions of 33 percent reporting an 'increase', a 'decrease' and 'stays the same'. Among male respondents, 50 percent reported that their decisionmaking power 'stays the same', 28-40 percent indicated an increase and 10-22 percent indicated a decrease in their decision-making power.

A second set of questions relating to decisions over freedom of movement and bodily integrity (including issues of personal consent and reproductive rights) ${ }^{26}$ showed that around $46-55$ percent of female respondents considered themselves to have 'no involvement', while those who made 'joint decisions' ranged from 23 percent to 31 percent, while only 10-17 percent considered themselves to be the 'decision maker' on these matters. Women's responses in relation to the drought's impact were inconclusive, with the exception of decision making around migration and displacement, where 46 percent of women reported a decrease in decision making, followed by 42 percent reporting an increase and 12 percent saying that it 'stayed the same'. In terms of male responses on household decision making regarding freedom of movement, 33-35 percent reported themselves to be the 'joint decision maker', followed by $36-56$ percent who said that they were the 'sole decision maker'. The majority of male respondents (55-64 percent) reported that their decision making had 'stayed the same' during the current drought.

A third set of questions related to decisions regarding children, as shown in Table 1. The only significant divergence from the general pattern of male/female decision making was around FGM/C, where 43 percent of female respondents reported being the sole decision maker, in comparison with a relatively high percentage (36 percent) of men who reported having 'no involvement' at all. From the responses provided, it seems that the drought has been a largely disempowering experience for both women and men, and a perceived decrease in decision-making power for men does not imply that the decision-making power of women has increased. Approximately 50 percent of male respondents said that their decision-making power had remained the same during the drought. 
Table 1: Oxfam study on gender-related decision making among 179 respondents in Afar and Somali regions

\begin{tabular}{|l|l|l|l|l|l|l|}
\hline & \multicolumn{2}{|l}{ 'No involvement' } & \multicolumn{3}{l|}{$\begin{array}{l}\text { 'Joint decision } \\
\text { maker' }\end{array}$} & \multicolumn{2}{l|}{$\begin{array}{l}\text { 'Sole decision } \\
\text { maker' }\end{array}$} \\
\cline { 2 - 7 } & Female & Male & Female & Male & Female & Male \\
\hline Whether to have another child & $62 \%$ & $26 \%$ & $27 \%$ & $53 \%$ & $7 \%$ & $12 \%$ \\
\hline Circumcision of boys & $60 \%$ & $6 \%$ & $26 \%$ & $60 \%$ & $11 \%$ & $31 \%$ \\
\hline FGM/C of girls & $29 \%$ & $36 \%$ & $23 \%$ & $41 \%$ & $43 \%$ & $14 \%$ \\
\hline Accessing healthcare for children & $47 \%$ & $5 \%$ & $32 \%$ & $71 \%$ & $15 \%$ & $18 \%$ \\
\hline Whether children attend school & $41 \%$ & $6 \%$ & $40 \%$ & $67 \%$ & $12 \%$ & $24 \%$ \\
\hline Arranging marriage & $39 \%$ & $9 \%$ & $45 \%$ & $69 \%$ & $11 \%$ & $15 \%$ \\
\hline
\end{tabular}

Among male respondents, 72 percent reported having been consulted in community decision making relating to the drought, in comparison with 45 percent of female respondents. Women also reported lower levels of activity (16 percent) in community associations such as religious organizations, women's groups and cooperatives, and those who were involved were predominantly engaged only as members. In contrast, a slightly higher percentage of men (24 percent) reported being part of religious organizations, cooperatives and political organizations -80 percent as members, while 20 percent held leadership positions. Furthermore, 95 percent of active men continued to be active during the drought, with continuing female participation at only 66 percent.

\section{CHANGING GENDER DYNAMICS AND COPING STRATEGIES}

During the current drought, women, men, girls and boys have been differently affected and have used different coping strategies. The following key points reveal the gender dynamics and the coping strategies used by communities to mitigate the effects of the drought.

\subsection{Productive work}

In Afar and Somali regions, the drought has reduced the prevalence of productive, income-generating and remunerated activities for women and men, with no noticeable shift in the gendered division of labour. Migrating with livestock (where still possible) continues to be carried out by men (90 percent) and boys ( 50 percent). While there is a noticeable involvement of women ( 20 percent) and girls (20 percent) in productive work, the majority are from female-headed households or are women whose husbands are temporarily away. Those households who are still able to derive some income from livestock-related livelihood activities do so with significantly fewer and smaller livestock (sheep and goats, rather than camels or cattle). Slaughtering and selling livestock continues to be an activity predominantly carried out by men ( 81 percent), as is keeping cattle and camels (62 percent of men and 50 percent of boys), with limited female engagement ( 9 percent).

Female-dominated activities, such as traditional milk processing, petty trade and production of handicrafts, have also been significantly reduced. Traditional milk processing is the only livestock- 
related activity exclusively carried out by women (up to 98 percent); however, only 46 percent reported that this activity was still being done in the context of the current drought (and only for household consumption). Petty trade, an activity generally carried out by women, has also decreased over the course of the drought, being carried out by only 10 percent of households. Similarly, there has been a reduction in making and selling handicrafts, with only 27 percent of households engaging in this activity due to the limited availability of raw materials, particularly for ropes. One man in Asangalo kebele reported: 'Before the drought, women used to produce handmade ropes used to fasten camel loads $(Y e A a)$ - now, due to the drought, the plant is not growing.'

The only discernible shift in the gendered division of labour relates to the increased disposition of women to engage in cash-for-work activities, and of husbands to authorize their wives' participation in these schemes (particularly in Afar Region).

\subsection{Reproductive care activities}

In comparison with the significant reduction of productive and income-generating work, unpaid reproductive labour (predominantly female labour) has shown an increase during the current drought. While it has been going on, 98 percent of households reported fetching water, and 94 percent and 98 percent of households respectively collected firewood in Afar and Somali regions. This increase in reproductive workload relates to drought-induced scarcity. Women have to walk further to find water, and they also have to dig for water (as it is covered by mud overnight), wait longer for their turn and go several times a day (because of limited water). This situation is exacerbated by the loss of livestock which could have served as a means to transport the water: 'We lost our donkey, so we carry the jerry cans on our backs' (FGD, Hadkaley, women). Frequently carrying heavy loads could have further health consequences for women, such as kidney and back pain. Especially in Arabi kebele, women made recurrent references to mandheli, a female-specific abdominal pain related to heavy work. Women also reported having sustained injuries as a result of falling into the pond (FGD, Asbuli, women).

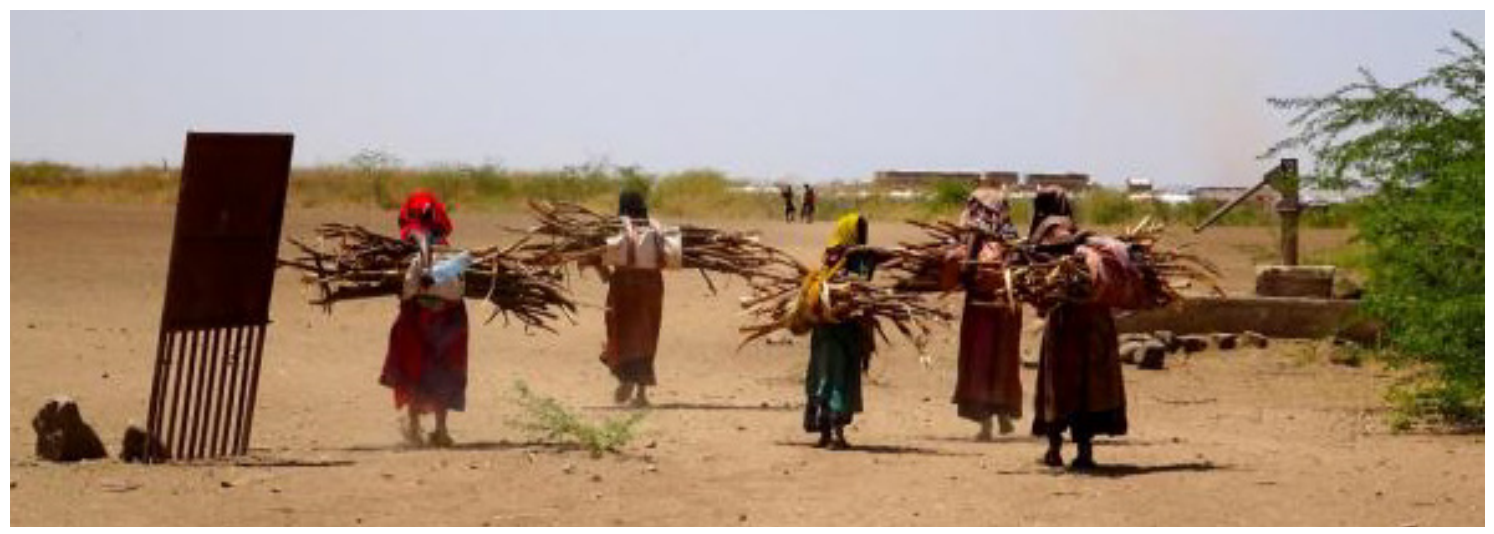

Women collecting firewood. Asbuli Kebele, Erer Woreda, Siti Zone, March 2016. Photo credit: Luisa Dietrich.

Despite it being considered female labour, as a result of the drought men do engage in unpaid reproductive activities outside the home, especially when these are considered physically demanding or involve increased protection concerns: 34 percent of men reported fetching water, while 50 percent of men go to community mills that can be far from the community. This change in the gendered division of labour is allowing for collaborative work: 'Men and boys dig the pond, then women and girls fetch the water. Before the drought, only women and girls went to fetch water, but now boys also fetch water and men support the women' (FGD, Hadkaley, women). However, men continue to face stigmatization and ridicule when cooking, cleaning the house or washing clothes, and report feeling uncomfortable transgressing traditional gender roles: 'Actually we can't do what women do, we can't be women. They should do their work, while we do our work' (FGD, Asbuli, men). 


\subsection{Community activities}

The level of engagement in community activities has been reduced over the course of the drought; only 32 percent of households reported being involved in the maintenance of water points, 34 percent in the construction of roads and 30 percent in the protection of grazing land. Men, from both IDP and host communities, tend to be more involved than women in community activities, and also reported being more consulted in decision making about these activities than women are.

Table 2: Household engagement in community activities among 179 respondents in Afar and Somali regions

\begin{tabular}{|c|c|c|}
\hline Community activity & Men & Women \\
\hline Maintenance of water points & $92 \%$ & $23 \%$ \\
\hline Construction of roads & $100 \%$ & $34 \%$ \\
\hline Community level negotiations ${ }^{27}$ & $99 \%$ & $6 \%$ \\
\hline Grazing land protection & $92 \%$ & $22 \%$ \\
\hline
\end{tabular}

\subsection{Coping strategies}

\section{Moving to IDP settlements}

In pastoralist households, it is predominantly adult women with young children who resettle in IDP camps. The decision to move to IDP settlements is considered by most pastoralists as a last resort in the search for food, water and humanitarian assistance, after losing most of their livestock. This is despite the fact that, for most, their places of origin are nearby: 70 percent of IDP respondents reported that their home kebele was less than two hours away, 15 percent reported that it was between 2.5 hours and two days away, while another 15 percent reported it to be more than two days away. Due to the loss of pack animals, many IDPs were unable to bring belongings, such as household utensils, with them: 'Those who lost all livestock came destitute to the IDP centres' (FGD, Asbuli, men). In this context, IDPs rely on support provided by host community households (often with kinship relations), which includes the provision of clothes and household utensils and feeding displaced children. Among IDPs in Siti Zone, 100 percent of male respondents and 87 percent of female respondents felt welcome in the new kebele. However, as new households arrive every week, resource scarcity is increasingly placing a strain on the host community's capacity to support IDPs. In consequence, humanitarian assistance should consider targeting host communities as well as IDPs, in order to prevent tensions arising around resource scarcity.

\section{Moving to urban centres or abroad for work}

The Oxfam study of Somali and Afar regions found that many men, adolescent boys and girls are migrating to urban centres in search of job opportunities. Men tend to look for casual labour, while boys might also continue their education. All kebeles analyzed reported that adolescent girls were moving abroad, predominantly to Dijbouti, to work as housemaids and servants. References to adolescent boys migrating also emerged, in their case to places even further afield, such as Saudi Arabia or Europe (FGD, Arabi, men). The CARE study in East and West Harerge, Afar and South Gonder likewise showed that adolescent girls mostly share their mothers' role in the domestic sphere, but at times migrate to other towns to find work as housemaids and support their family through remittances. Men and adolescent boys often use migration as a coping mechanism. In addition, they are involved in daily labour or cattle trading, or they rent their camels for the transportation of 
commercial commodities in Afar. In East Harerge, some of the women with the least income also go to town to work as daily labourers, carrying water containers for money. Men also do labour work or travel to distant places as daily labourers - for example, carrying khat (a stimulant plant) from farm to market place or collecting stones for construction and loading them onto vehicles. Both men and women work on removing impurities from commercial corn brought by traders. In Afar, men and boys travel to nearby towns to work as daily labourers on sugar cane plantations or road construction.

\section{Petty trade}

In East and West Harerge, Afar and South Gonder, women are involved in petty trade as a key coping mechanism. Women in East Harerge make handicrafts (sifet) and sell khat, cooked cereals (nifro), firewood and charcoal. In West Harerge, women are earning an income from pottery making, weaving and braiding hair, selling wood and charcoal, or begging. Women are also involved in daily labour and get paid for activities such as washing clothes, fetching water, goat herding and weeding. In Afar, women are able to sell wood, use unga (a plant that grows in the area- to make ornaments), make beds (aloyita) and milking utensils (ayini) and prepare traditional Afar house construction materials. Men are also skilled in crafting milk storage and milking utensils (kora and koba).

\section{Other coping mechanisms}

In East Harerge and South Gonder, some female-headed households are supported by a Village Savings and Loan Association (VSLA), which provides them with a means of financial income and an opportunity to interact with other women in the community. In South Gonder people also reported taking loans from the Amhara Credit and Saving Association.

\subsection{Debt}

While in previous droughts buying on credit was a common coping mechanism, with buyers paying back in cash or in-kind after the rains, this is increasingly becoming impossible, as petty traders have stopped giving out food on credit due to concerns that pastoralists and agro-pastoralists will not be able to pay back their debts. In relation to the increased debt burden, a female respondent reported: 'We lost our social status in the community' (FGD, Galaiso, women). There are no significant gendered differences in terms of household debt, with 25 percent of men reporting increased debt due to the drought against 24 percent of women (see Figure 4 above). Data from the quantitative survey on household debt suggest that approximately 40 percent of respondents are indebted. There is no significant gendered variation: for women the figure is 42 percent and for men 47 percent. When questioned about lenders, it appears that the primary lenders are neighbours and relatives (65 percent), followed by traders (43 percent). The majority of women ( 97 percent) use borrowed money to buy food, in comparison with 88 percent of men who reported the same. Borrowed money is also often spent on medical treatment (42 percent of men, 21 percent of women). 
Figure 7: What is borrowed money used for?

\section{All women}

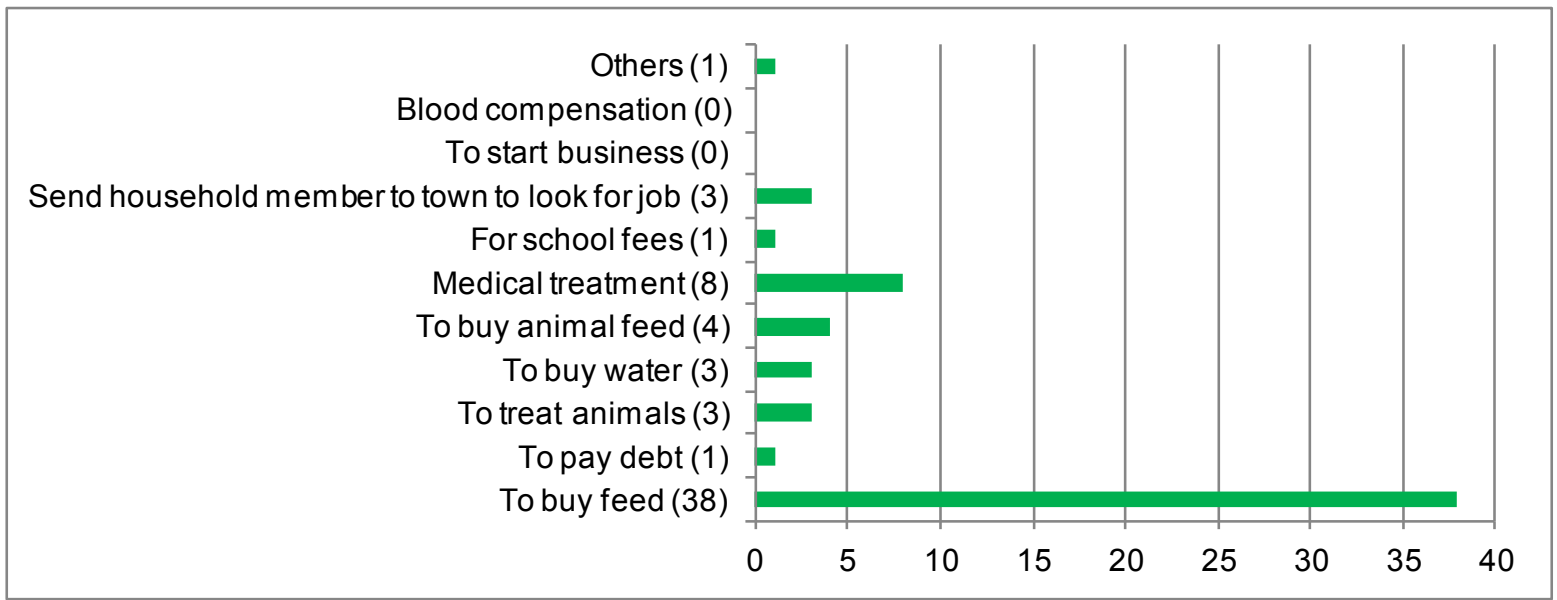

All men

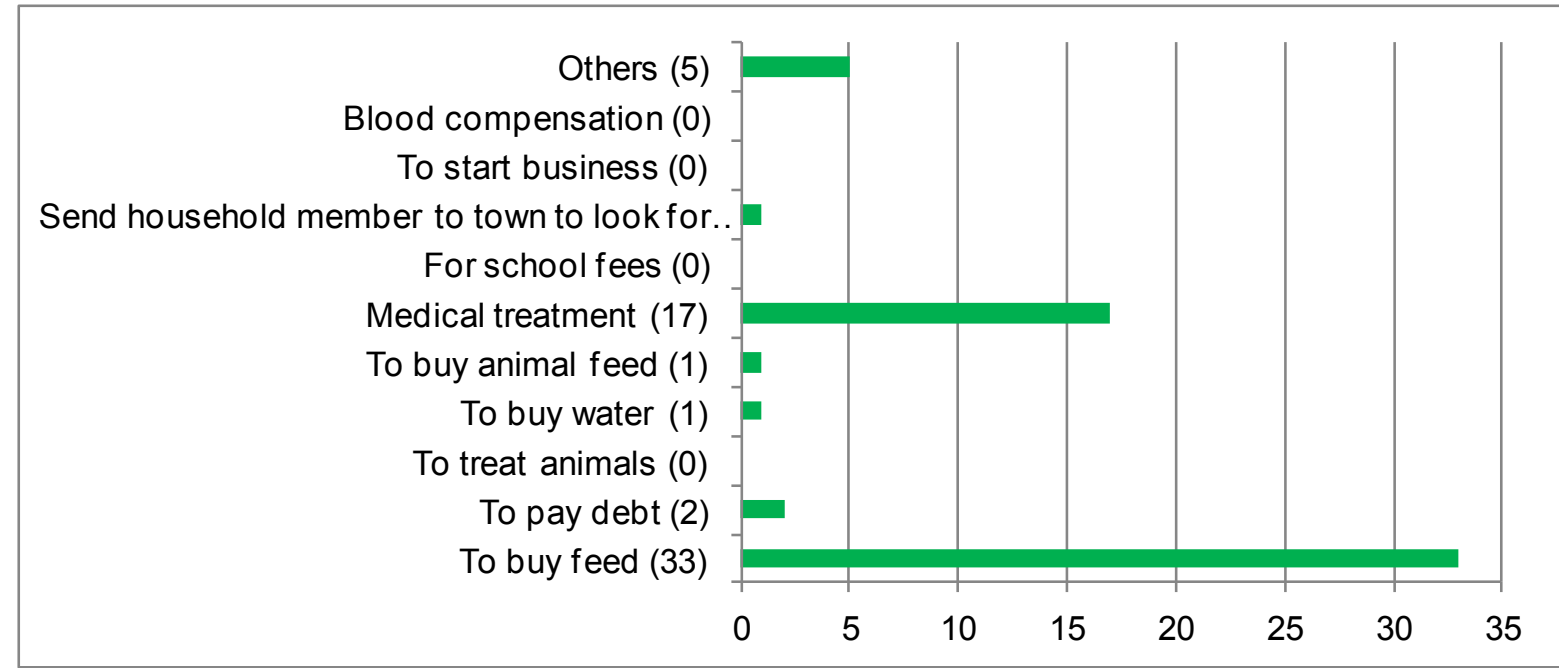

\section{PRIORITIES AND OPPORTUNITIES FOR GENDER-RESPONSIVE PROGRAMMING}

\subsection{Priority needs}

In terms of priority needs, there is neither a significant gendered pattern nor a great difference across regions. The most urgent needs in all the regions analyzed relate to the provision of water in sufficient quality and quantity at reliable times. Food is requested in sufficient quantity, ready to use (due to a lack of local milling services), and which can be prepared with small amounts of water. Among female respondents, considerations around nutritious and diverse food (including complementary food for infants) are recurrent. In addition, NFI priorities include clothing, soap, jerry cans, cooking utensils (including frying pans), blankets and female dignity kits. Explorations into women's specific needs around dignity kits reveal the need for dresses, scarves and shoes, as well as black cloth to address menstrual hygiene needs. While the use of underwear is not prevalent, especially among pastoralist women and girls, female respondents signalled a disposition to use underwear if it was distributed. Another key priority identified is cash distribution options, either through cash-for-work/training or unconditional cash transfers to enable recipients to buy preferred food, while also strengthening the 
capacity of local petty traders (predominantly women). Saving remaining livestock constitutes another key priority and requires provision of fodder and water, as well as veterinary health support.

\subsection{Ideas of affected men and women}

\section{Long-term priorities}

Long-term needs were largely proposed by men in agro-pastoralist communities, and included investment in infrastructure - such as the rehabilitation of irrigation systems (Arabi, Somali), diverting the course of rivers (Asangola, Afar), dam construction (Hadkaley, Somali) and building road infrastructure. Pastoralist households focused on livestock distribution to enable them to return eventually to their preferred livelihood options, as well as training and distribution of (farming) equipment for alternative livelihood options and support for pastoralists to settle. Requests from women (in all studied kebeles) focused on support to women's cooperatives and employment creation, as well as grants for small businesses, especially around petty trade and food preparation.

\section{Preferred cash-for-work activities}

Generally speaking, men prefer to do physical labour on infrastructure and construction (latrines, houses, roads, boreholes), while women are interested in income-generating activities, even though for some women this might be a departure from the traditional gendered division of labour.

\section{Figure 8: Preferred cash-for-work activities for women and men}

\section{Women}

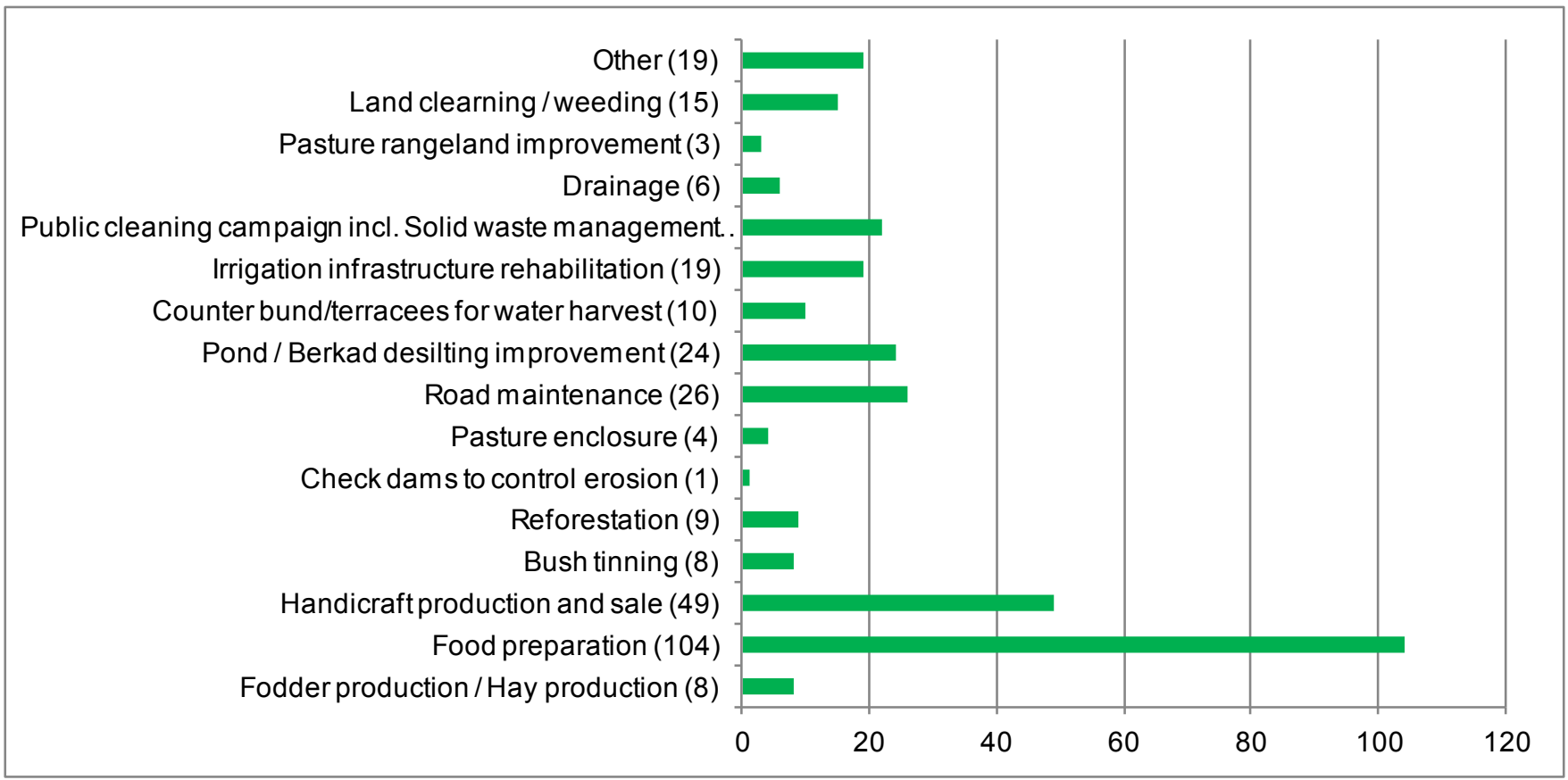


Men

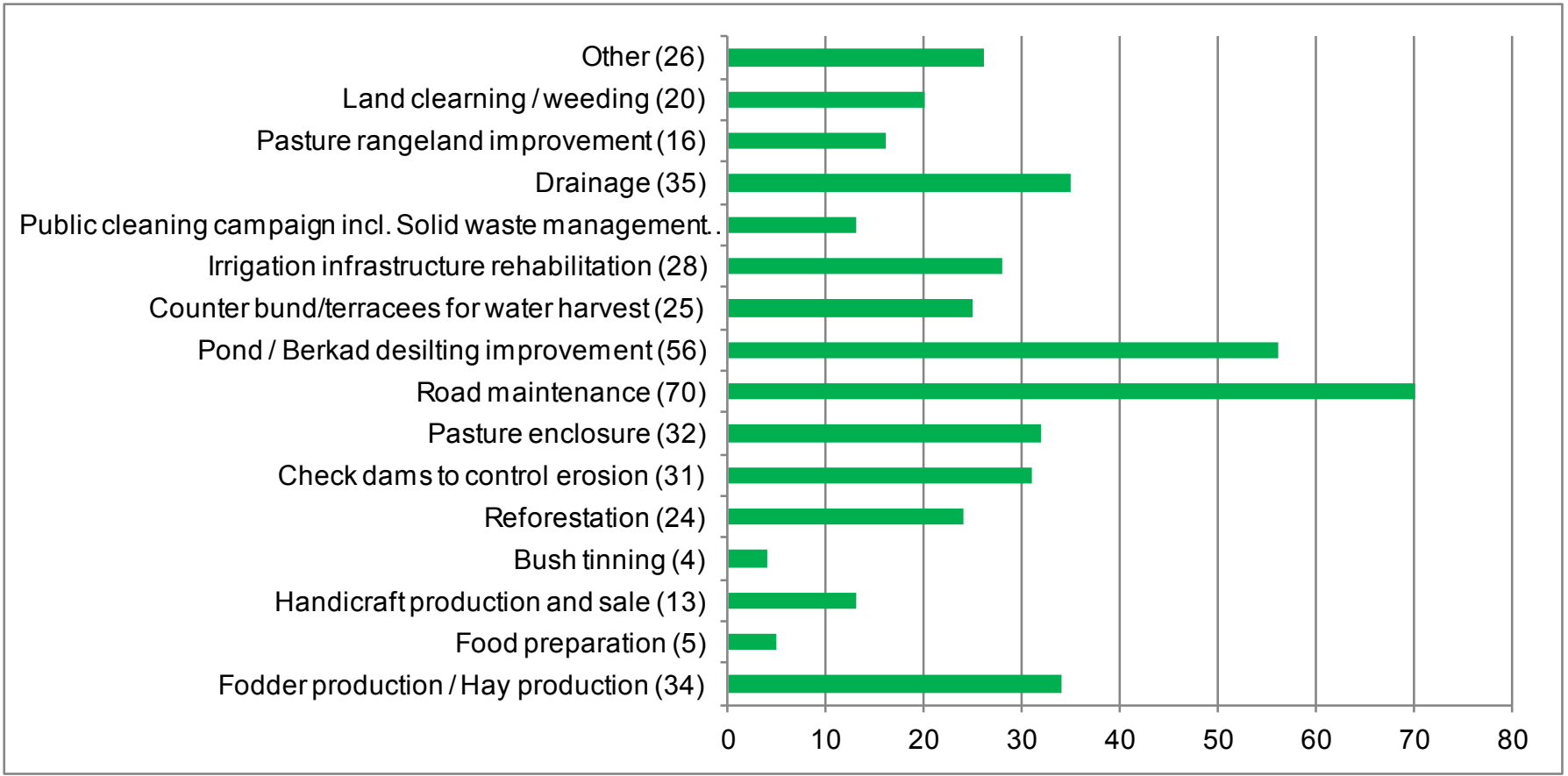

Analysis of primary data suggests different gendered expectations attached to CFW activities (Figure 9). While in Somali Region joint CFW activities between women and men are possible, in Afar it is widely felt that women are not supposed to mix with men. Despite being overburdened with unpaid reproductive work, women show an interest in CFW opportunities. Women in Asbuli pointed out that they have engaged in casual labour previously: 'We worked in construction of guesthouses and constructed community latrines.' However, women may not take on CFW activities unless these are near their homes (FGD, Asangalo, men). The most relevant change noted is that since the drought began, men in Afar are now willing for their wives to go out and work - 'As long as women do not mix with men alone and do not go too far away' (FGD, Asangalo, men).

Humanitarian CFW activities need to monitor closely intra-household tensions that might lead to verbal or physical abuse. As already highlighted, most household tensions arise around decisions on how to spend money. While women may engage in CFW activities and may even receive more cash than their husbands, respondents were not in agreement about who decides and how the money is spent: 'Women have to get permission from the husband [to work], then she will decide what she has to do with the money' (FGD, Asbuli, women). Similar comments were made in the Hadkaley women's FGD: 'Ultimately, it is the husband who decides on how the money [the woman] earns is to be spent for that particular household only. However, she has the right to decide whether or not he is going to share the money with his other wives if he happens to be in a polygamous marriage - he will not do so without her full permission. In Afar region also the husband decides on whatever resource he earns personally' and also he decides on his wife's earning (FGD, Asangalo, men).

\section{Cash transfers}

Unconditional cash transfers could be important in returning some form of agency to the droughtaffected population, in particular by enabling them to buy their most preferred foods, to buy adequate food for infants and to invest in petty trade. Cash provided in envelopes seems to be the most practicable solution, as access to mobile banking services is limited. 


\section{HUMANITARIAN COORDINATION}

The Government of Ethiopia has taken the lead to coordinate the current emergency drought response, and it has allocated significant budgetary resources to address the needs involved in saving lives. UN agencies, INGOs, NGOs and other humanitarian organizations participated in developing the Humanitarian Requirements Document (HRD) 2016, with the support of the government. The HRD primarily focuses on saving lives and on protecting and restoring livelihoods so that the affected communities will quickly be able to recover from the situation and avoid further harm.

According to the HRD assessment, the major priority needs of the affected population, categorized into clusters, include agriculture, nutrition, education, WASH, protection, health and shelter. To enhance the resilience of the communities affected by the drought, there is also a need to separate the humanitarian response and commence long-term development assistance.

Humanitarian partners should also be committed to a 'do no harm' approach and to prioritizing considerations of gender equality and women's rights, taking into account the different vulnerabilities that women, men, boys and girls face in accessing humanitarian assistance. Programmes must always include female community members, beyond the indicator for female-headed households, which can be misleading. Many women are temporarily heading their households as male heads move in search of livelihoods and pasture, according to the HRD.

The gender analyses carried out by Oxfam and CARE highlight the need to strengthen coordination among different actors at regional and national levels in order to maximize the impact of the limited resources and to provide reliable information for decision making. There is a demand for humanitarian assistance to proactively contribute to effective coordination among key actors, especially for WASH, seeds/inputs, cash programming, the Gender in Humanitarian Action Working Group and coordination of support to IDP populations. A summary of action plans by Working Group members is given in Annex 1.

\section{RECOMMENDATIONS}

\subsection{Enhance coordination mechanisms to address complex emergencies}

\section{Address priority needs of the drought-affected population}

Ensure a coordinated approach between the regional government, the UN system, local and international organizations and community authorities in order to address the drought-affected population's most pressing needs for water and food. Safe water provision in sufficient quantity is required in all of the kebeles assessed. Similarly, the provision of food in sufficient quality and quantity has been requested, as well as mobile milling solutions. Opportunities to diversify food provision, including digestible, nutritious and greater variety of food, should be seized.

\section{Include gendered considerations in recovery interventions}

If decisions are made to restore the preferred livelihood options of pastoralist households, the equal inclusion of women in livestock restocking needs to be considered, providing options for sole or joint ownership (together with awareness-raising activities around gendered patterns of access to and control over resources). For those IDP pastoralist households planning to settle permanently in host communities, training on alternative livelihood options needs to include preferred opportunities for female beneficiaries, while (farming) equipment should be distributed equally among female and male beneficiaries. Recovery interventions relating to water source management and infrastructure projects 
should maximize opportunities to enhance women's participation and leadership at community level. In addition, targeted support to mixed and women's cooperatives, as well as access to grants for small businesses (especially around petty trade and food processing), could increase women's economic status.

Concerned actors should engage jointly in recovery interventions aimed at creating access to education and health services in the drought-affected areas.

\section{Improved collaboration}

Improved collaboration is needed between NGOs such as Oxfam, CARE and UN agencies, particularly in lobbying the government to crack down on illegal brokers who arrange early marriages.

\section{Monitoring of GBV and harmful traditional practices}

Monitoring of GBV and harmful traditional practices (HTPs) should be a part of all emergency project monitoring and evaluation plans and should be done jointly with relevant government offices, such as Ministry of Women and Childeren Affairs, and community HTP committees. GBV and HTP should be key evaluation areas for all interventions assessed at the end of emergency response projects.

\subsection{Improve targeting practices for humanitarian assistance}

\section{Improve targeting of vulnerable groups, while reducing levels of vulnerability}

Extend the categorization of vulnerable populations from existing gender and age considerations to include polygamous households and households living at sub-kebele level. Differentiated targeting practices should address and reduce levels of vulnerability, and should focus on inclusive information provision and registration (for widows, divorced or separated women and households at sub-kebele level), as well as distributing specific items (complementary food for infants, elderly or pregnant women) or humanitarian assistance in greater quantities (to polygamous households, pregnant women).

\section{Extend targeting practices to include IDPs and host communities}

Despite prevailing collaborative relationships between IDPs and host communities, resource scarcity limits host communities' capacity to provide continuous support. Including host communities in the provision of humanitarian assistance, such as cash-for-work or unconditional cash grants, could contribute to strengthening the resilience of affected communities. In addition, ways should be considered to increase the national average size of drought-affected households, from the national average household size of six members to 7.5 members.

\subsection{Seize opportunities to transform gender dynamics}

\section{Address the psychosocial impact on men}

Increase levels of agency through targeted cash-for-work activities for men, particularly around physical labour. Consider targeting male beneficiaries with CFW schemes that support vulnerable populations (elderly and disabled people and pregnant or lactating women). Seize the opportunity to increase men's awareness of women's overburden of work, and explore options for engaging men in reproductive labour outside the house, thus contributing to shifts in the gendered division of labour. 
Take measures to reduce women's (unpaid) reproductive workload through holistic programme design

Seize opportunities to reduce women's workload through the provision of safe and reliable water trucking, the rehabilitation of boreholes, the provision of water harvest materials and by supporting the government's efforts to complete piped water systems. Consider distributing locally produced fuelefficient stoves, as well as providing food that requires less water/less cooking time. It is also very important to set up provision of childcare facilities for female-headed households so that they can access livelihoods opportunities and participate in community leadership.

\subsection{Enhance holistic water, sanitation and hygiene interventions}

\section{Install gender-specific water, sanitation and hygiene hardware}

Engage in participatory and inclusive consultation mechanisms with a diverse group of communities on the most appropriate design and siting of locked latrines, safe and well-lit bathing spaces and solid waste management systems. Adapt the ratio of female-male latrines to the local context, in particular in IDP settlements that are predominantly composed of women. Ensure separate locations of latrines for females and males, with locks and lighting.

\section{Seize the opportunity to significantly scale up public health promotion activities}

Step up public health promotion training, with a special emphasis on hand washing, water treatment and cleaning of jerry cans. Increase the number of female community health volunteers, and increase women's active participation and leadership in water user committees and in monitoring schemes to ensure adequate water quality.

\subsection{Expand emergency food security and support for vulnerable livelihoods}

\section{Expand distribution of NFIs}

The most pressing NFI needs include clothing (for women and men), soap and detergent (bars tend to require less water than powder), shoes (different sizes), jerry cans, water storage, cooking utensils (including frying pans), fuel-efficient stoves and blankets. Female dignity kits should include shoes, clothes (scarf, dress and underwear), as well as dark cloth for women to make reusable sanitary pads and flashlights (wind-up or with batteries).

\section{Expand cash transfer programmes to increase the agency of beneficiaries}

Increase cash transfers to enhance the agency of the beneficiary population, in particular of those populations considered vulnerable. Include the most preferred and complementary food items, and strengthen the capacity of petty traders to ensure that these foods are on sale. Consider food vouchers, and schemes involving cash-for-learning and cash-for-travel (for beneficiary registration at sub-kebele level).

\subsection{Institutionalize protection and safe programming}

\section{Increase engagement with community leaders to monitor and prevent SGBV and human trafficking}

Establish the prevalence of SGBV in the local context and raise awareness among kebele authorities and religious leaders around combating violence against women and girls and preventing human 
trafficking among girls and boys, while strengthening collaborative community coping mechanisms (such as going to water points in mixed-gender groups).

\section{Strengthen inter-agency referral systems}

Increase inter-agency cooperation, including with the Ministry of Women and Children Affairs, and work across the Gender in Humanitarian Action Working Group and the Protection Cluster in order to map a referral pathway for survivors of SGBV and victims of trafficking.

\section{Integrate psychosocial support activities into emergency response where possible}

If integration of pyschosocial support into the emergency response is not possible within the means of the project, link with other long-term projects and services that are delivering psychosocial support. 


\section{Annex 1: Summary of action plans by the Gender in Humanitarian Action Working Group}

\section{Promoting gender equality through internal practice}

- Allocate adequate and constant budgets to address gender inequalities at organizational level

- Recruit staff based on experience, understanding and commitment to gender equality

- Ensure that workplace policy and procedure are in place, mainstreamed and implemented appropriately

- Ensure the accountability of senior management

- Include gender capacity of senior staff with partner organizations as criterion of selection

- Provide capacity development training on gender minimum standards and gender mainstreaming for technical and senior management staff and partners. Provide refresher and post-training assessments

- Improve the gender balance of staff in all positions and also beneficiaries committees

- Appoint a dedicated gender expert or gender focal person

- Review and implement workplace policies and procedures of own organization and partners, and update and revise when necessary

- Review and strengthen feedback and reporting mechanisms on workplace safety

- Revisit monitoring framework of the organization to make it gender-responsive

- Undertake a staff capacity gap assessment on the promotion of gender equality

- Provide induction packs and training on minimum standards for newly recruited staff

- Include gender-targeted activities throughout the project cycle, beginning from the development of proposals

\section{Gender analysis (GA) through the programme cycle}

- Provide training on how to undertake GA and how to use assessment tools, and ensure that GA is done before project design

- Prepare a GA checklist and formulate a team to conduct GA

- Share the findings of GA with partners and other I/NGOs

- Use information from GA to inform disaster risk reduction (DRR) programming

- Ensure that GA is included in contingency planning

- Promote accountability and learning mechanisms among the broader community

- Conduct staff gender capacity assessment and design and carry out regular trainings to promote gender capacity 


\section{Participation, dignity and empowerment}

- Ensure that activities are accessible to vulnerable groups (during project design) and track the information in M\&E

- Hold regular reflections on gender issues during emergencies and document and share lessons learned

- Provide formal trainings and informal support to staff and partner organizations to ensure access and participation of all vulnerable groups

- Ensure that the rights and dignity of women and girls are promoted during the programme cycle

- Incorporate men and boys into programming and support them to ensure that the needs and rights of women and girls are addressed in emergencies

\section{Safe programming and prevention of sexual exploitation and abuse (PSEA)}

- Establish committees to handle complaints at community level

- Develop reporting mechanisms for GBV and SEA and ensure their implementation

- Adopt best policies from other organizations; adopt SEA policy endorsed by management

- Assign a focal person and provide them with proper training

- Carry out induction on GBV and PSEA policies and complaint mechanisms for all staff at time of recruitment

- Work closely with local authorities and local organizations working on GBV

- Visit field officers (partners) and help revise and mainstream PSEA and GBV policies

- Allocate adequate budgets to finance GBV and SEA work

- Conduct service mapping on GBV

- Advocate for using clusters, working groups and gender champions, and share best practices and learning

\section{Coordination on gender equality - working together}

- Identify network clusters and working groups on gender equality

- Conduct joint planning and development of programmes that incorporate gender equality

- Coordinate with members of the working group (collaborating with other organizations) to promote gender equality

- Design a learning exchange session with the working group on at least a quarterly basis 


\section{NOTES}

1 Oxfam, CARE, Concern Worldwide, GOAL, ChildFund, the Consortium of Christian Relief and Development Associations (CCRDA), Sustainable Environment and Development Action (SEDA) and the Rift Valley Children and Women Development Organization (RCWDO).

2 This 18-month-long ECHO-funded project aims to catalyze change within the humanitarian sector by institutionalizing gender mainstreaming in emergencies and strengthening accountability to enable response capacity for adapted assistance to meet the needs of women, girls, boys and men.

3 Central Statistical Agency (2013). Population Projection of Ethiopia for all Regions at Woreda Level from 20142017. http://www.csa.gov.et/images/general/news/pop_pro_wer_2014-2017_final (accessed 8 July 2016)

4 National Planning Commission (2016). Growth and Transformation Plan II (GTP II) (2015/16-2019/20). Volume

I: Main text.

5 Ibid.

6 Ibid.

7 Central Statistical Agency (2014). Ethiopia Mini Demographic and Health Survey.

http://www.unicef.org/ethiopia/Mini_DHS_2014_Final_Report.pdf (accessed 10 July 2016)

8 United Nations Development Programme (2015). Human Development Report 2015. New York, USA.

9 Central Statistical Agency (2014). Ethiopia Mini Demographic and Health Survey, op. cit.

10 Government of Ethiopia and Humanitarian Partners (2016). Ethiopia Humanitarian Requirements Document

2016. https://www.humanitarianresponse.info/en/system/files/documents/files/ethiopia_hrd_2016.pdf

11 lbid.

12 Government of Ethiopia and Humanitarian Partners (2016). Ethiopia Humanitarian Requirements Document 2016. https://www.humanitarianresponse.info/en/system/files/documents/files/ethiopia_hrd_2016.pdf

15 Ibid.

16 lbid.

17 lbid.

18 Ethiopia Ministry of Finance and Economic Development (2014). Growth and Transformation Plan Progress Report for FY 2012/13.

19 Government of Ethiopia and Humanitarian Partners (2016). Ethiopia Humanitarian Requirements Document 2016, op. cit.

20 A. Sasvari (2016). Protection Analysis Drought Response Ethiopia. Internal report. Oxfam GB.

21 Awuf awufu is a traditional way of asking for forgiveness for any kind of wrong-doing.

22WHO(2016) Female genital mutilation, Fact sheet

23 OCHCR, UNAIDS, UNDP, UNECA, UNESCO, UNFPA, UNHCR, UNICEF, UNIFEM, WHO (2008). Eliminating Female Genital Mutilation: An interagency statement.

http://www.un.org/womenwatch/daw/csw/csw52/statements_missions/Interagency_Statement_on_Eliminating_FG M.pdf

24 UN Women (2014). Preliminary Gender Profile of Ethiopia. http://africa.unwomen.org/en/digitallibrary/publications/2015/12/preliminary-gender-profile-of-ethiopia

25 Questions related to working to earn money oneself, how income is spent, buying for household consumption and buying or selling assets.

26 Questions related to freedom to visit birth relatives, participation in decisions around household migration/displacement and 'accessing healthcare for yourself'.

27 These can involve negotiations after the death of one or more persons in a community or household and involve negotiating the amount of compensation from others. 